\title{
Carbon Footprint Assessment of a Novel Bio-Based Composite for Building Insulation
}

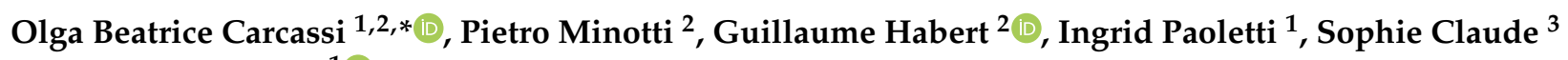 \\ and Francesco Pittau ${ }^{1}$ (i)
}

1 Department of Architecture, Built Environment and Construction Engineering (ABC), Politecnico di Milano, Via G. Ponzio 31, 20133 Milano, Italy; ingrid.paoletti@polimi.it (I.P.); francesco.pittau@polimi.it (F.P.)

2 Chair of Sustainable Construction, Eidgenössische Technische Hochschule (ETH) Zurich, Stefano Francini Platz 5, CH-8093 Zurich, Switzerland; pminotti@student.ethz.ch (P.M.); habert@ibi.baug.ethz.ch (G.H.)

3 Laboratory for Materials and Construction Works Durability (LMDC), Institut National des Sciences Appliquées de Toulouse, Avenue de Rangueil 135, 31077 Toulouse, France; sclaude@insa-toulouse.fr

* Correspondence: olgabeatrice.carcassi@polimi.it

check for updates

Citation: Carcassi, O.B.; Minotti, P.; Habert, G.; Paoletti, I.; Claude, S.; Pittau, F. Carbon Footprint Assessment of a Novel Bio-Based Composite for Building Insulation. Sustainability 2022, 14, 1384. https:// doi.org/10.3390/su14031384

Academic Editor: Asterios Bakolas

Received: 10 December 2021

Accepted: 20 January 2022

Published: 26 January 2022

Publisher's Note: MDPI stays neutral with regard to jurisdictional claims in published maps and institutional affiliations.

Copyright: (c) 2022 by the authors. Licensee MDPI, Basel, Switzerland. This article is an open access article distributed under the terms and conditions of the Creative Commons Attribution (CC BY) license (https:// creativecommons.org/licenses/by/ $4.0 /)$.

\begin{abstract}
This research explores the carbon removal of a novel bio-insulation composite, here called MycoBamboo, based on the combination of bamboo particles and mycelium as binder. First, an attributional life cycle assessment (LCA) was performed to define the carbon footprint of a European bamboo plantation and a bio-insulation composite, as well as its ability to remove $\mathrm{CO}_{2}$ along its lifecycle at a laboratory scale. Secondly, the Global Worming Potential (GWP) was estimated through a dynamic LCA with selected end-of-life and technical replacement scenarios. Finally, a building wall application was analyzed to measure the carbon saving potential of the MycoBamboo when compared with alternative insulation materials applied as an exterior thermal insulation composite system. The results demonstrate that despite the negative GWP values of the biogenic $\mathrm{CO}_{2}$, the final Net-GWP was positive. The technical replacement scenarios had an influence on the final Net-GWP values, and a longer storage period is preferred to more frequent insulation substitution. The type of energy source and the deactivation phase play important roles in the mitigation of climate change. Therefore, to make the MycoBamboo competitive as an insulation system at the industrial scale, it is fundamental to identify alternative low-energy deactivation modes and shift all energy-intensity activities during the production phase to renewable energy.
\end{abstract}

Keywords: LCA; bamboo fibers; mycelium binder; biogenic carbon; façade renovation

\section{Introduction}

Buildings are responsible for a consistent share of total greenhouse gas emissions (GHGs), and contribute massively to the consumption of natural resources [1-3]. While intense research has been conducted in the field of optimizing GHG emissions during building operations, the embodied emissions related to the materials used in buildings have gained attention only in the past few decades [4]. Embodied emissions are those considered in the lifespan of a material, which are linked to the material's manufacture, transportation, construction and end-of-life disposal [5]. To mitigate the embodied emissions, recent studies have demonstrated the efficiency of substituting fossil-based materials with bio-based ones due to their carbon storage potential and reduced life-cycle emissions [6,7]. Among the different biogenic materials, the ones that come from biomass that grows back within 1-5 years, also called fast-growing or herbaceous biomass, are the most promising for use to mitigate climate change since they can store carbon much faster than trees [8]. Bamboo is one of the fastest-growing biomasses, and is characterized by a high carbon content [9]; however, this beneficial effect is limited if the bamboo is imported to Europe [10], since the mode of transport is relevant in terms of emissions [11]. To lower transportation emissions and to benefit from bamboo's unique features, such as rapid growth, high productivity and 
rapid ripening from the shoot [12], the interest in bamboo cultivations of phyllostachys edulis has been growing in Europe $[13,14]$. The growth patterns of bamboo differ from those of traditional wood, and beside the possibility of substituting wooden panels with bamboo ones, the quantity of bamboo particles generated as waste throughout bamboo's industrial chain can be consistent [15]. Typically, these particles exhibit good hygrothermal potentials that are linked to their natural fibrous structure [16]. By creating insulating materials out of this waste, from a circular economy perspective, one can address the need to lower the operational energy in buildings today while neutralizing the building's embodied emissions. Reducing the use of non-renewable resources is a key strategy in a circular economy; nonetheless, to improve the dimensional stability, fire resistance, and biotic degradation resistance of these bamboo-based solutions [17], mycelium-based insulation materials are an emerging category of potentially useful bio-composites. Mycelium is the vegetative part and the root structure of fungal organisms [18], and it has attracted increasing academic and commercial interest over the past few decades as a new form of low-energy bio-fabrication and waste upcycling $[19,20]$. Waste and residues are thus valorized rather than discarded, while fungal mycelium acts as a reinforcement in the matrix structure, creating a 100\% plastic-free and coherent material composite. Mycelium-based composites are noticeably less prone to ignition and flaming combustion, and therefore safer to use due to the high chitin/chitosan content and thermal stability, with degradation starting at temperatures greater than $220^{\circ} \mathrm{C}$ [21]. Taking advantage of the characteristics discussed above, mycelium offers an alternative fabrication paradigm, acting as a self-assembling glue, based on the growth of materials rather than on extraction.

In addition, the choice to use biological substances, such as bamboo particles, allows us to consider the regenerative capacity of the environment, as well as to store $\mathrm{CO}_{2}$ within buildings' skins. However, a considerable point of conflict within life-cycle assessment (LCA) is biogenic carbon accounting, used to quantify the carbon storage potential [22-24]. Carbon storage can be defined as the sequestration of carbon in products for a certain period, resulting in a temporary reduction in the $\mathrm{CO}_{2}$ concentration in the atmosphere [25]. The current LCA methodology does not consider when emissions occur, resulting in the impossibility of considering the temporary carbon storage and delayed emissions of biobased products [7]. To overcome this simplification, several studies of bio-based materials have been carried out using the dynamic LCA (dLCA) approach, which is able to model different timing of emissions and sequestrations related to different boundaries and endof-life options $[7,24,26]$. This model can also address the inconsistency between different time frames observed with traditional LCAs when replacing building assemblies and components during the life of buildings [4].

In this context, the goal of this study is to assess the carbon footprint of a novel biocomposite, MycoBamboo, as a novel insulation material for renovating building facades, and to analyze each process involved in its production. Despite their already established architectural potentials [27-30], the currently available literature and knowledge about the process efficiency and relative environmental impacts of these bio-based composites are very fragmented [31-34]. Indeed, the mycelium-based composites are new promising solutions for construction, and a deep understanding of their ability to mitigate the climate change over their life cycle is needed. Furthermore, when coupled with bamboo particles from phyllostachys edulis, the large carbon storage capacity of the involved fast-growing biomass contributes to reducing the Global Warming Potential (GWP). For this reason, a dLCA model was used to include biogenic $\mathrm{CO}_{2}$ in the assessment.

\section{Materials and Methods}

\subsection{Methodological Framework}

The carbon footprint of MycoBamboo composite fabricated at laboratory scale is here presented and the methodology adopted is represented as a schematic diagram in Figure 1. 


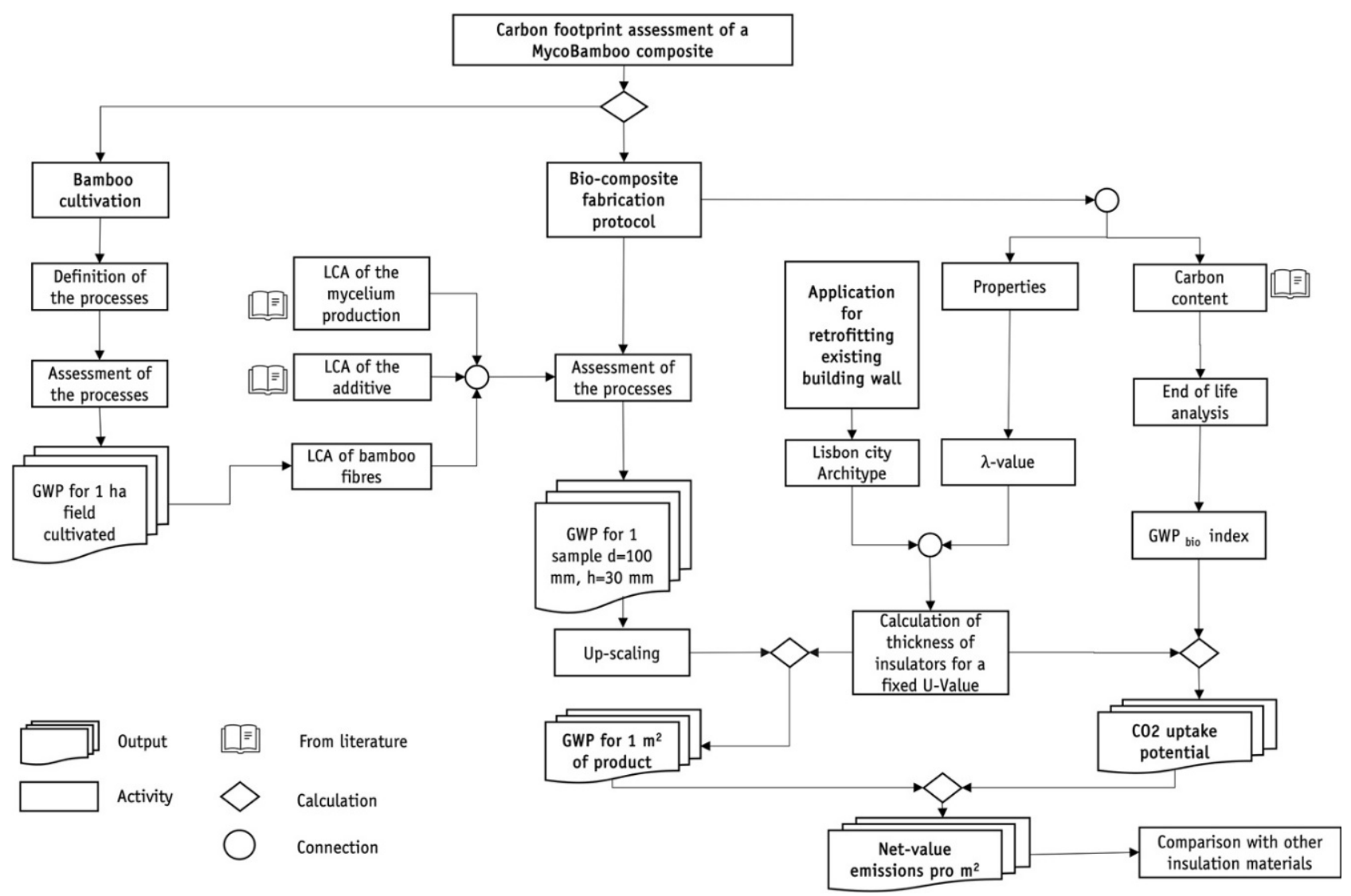

Figure 1. Schematic diagram of the performed LCA methodology.

The work was divided into four different phases. First, all the possible processes involved in selected bamboo cultivation were studied and analyzed through the guidelines of specialized bamboo farmers active in Italy [35]. Once all the inputs were collected and allocated, an LCA model was developed with the software SimaPro 9.2 [36] to analyze the GWP at 100 years (GWP-100) generated from 1 ha of bamboo cultivation. Data from the ecoinvent 3.8 database [37] were used for the definition of the Life Cycle Inventory (LCI) (see Table A1 in Appendix A). Secondly, the carbon emissions related to the fabrication of the MycoBamboo bio-composite were assessed according to the protocol developed at the laboratory scale. The input data flow for substrate preparation, as well as the output flow from the bamboo cultivation, with the addition of the transportation to the laboratory facilities, were included in the system's boundaries. The functional unit (FU) assumed to model the production at lab-scale was 1 sample, a circular prism with $\phi=100 \mathrm{~mm}$ and a thickness of $30 \mathrm{~mm}$. In parallel, the bio-composite was tested to understand the thermal conductivity via the Transient Plane Source (TPS) method, which is based on the use of a disk placed between two samples, called a Hot Disk, that produces a thermal impulse on the material under examination and measures the change of thermal resistance, with the additional calculation of the thermal diffusivity and heat capacity. Thirdly, the carbon uptake potential of MycoBamboo was determined through a dLCA to evaluate anaerobic composting as an EOL scenario, and for two storage periods, namely, 30 and 60 years. The resulting GWP of biogenic $\mathrm{CO}_{2}$ was finally added to the fossil GWP to obtain the Net-GWP.

Finally, an up-scaling of the results for $1 \mathrm{~m}^{2}$ of MycoBamboo, installed onsite as the exterior thermal insulation composite system (ETICS) in the renovation of an existing reference façade, was proposed to compare the novel insulation system with alternative bio-based and non-bio-based solutions with identical U-values. 


\subsection{Bamboo Cultivation}

A typical bamboo cultivation consists of three consequential phases, happening in different maturation periods of the plantation: (i) soil preparation, (ii) plantation, and (iii) cultivation management or maintenance. In Figure 2, the whole cultivation process, with agricultural activities, of bamboo growing is presented. The expected lifetime of a bamboo plantation under a continental climate is unknown. Moso bamboo is a perennial plant characterized by rapid growth and a long vegetative stage that lasts for decades or even longer before flowering. Recent studies have estimated that flowering, which causes the death of the plant, may take up to 100 years [38]. For this specific study, a reference service life of the plantation of 100 years was assumed.

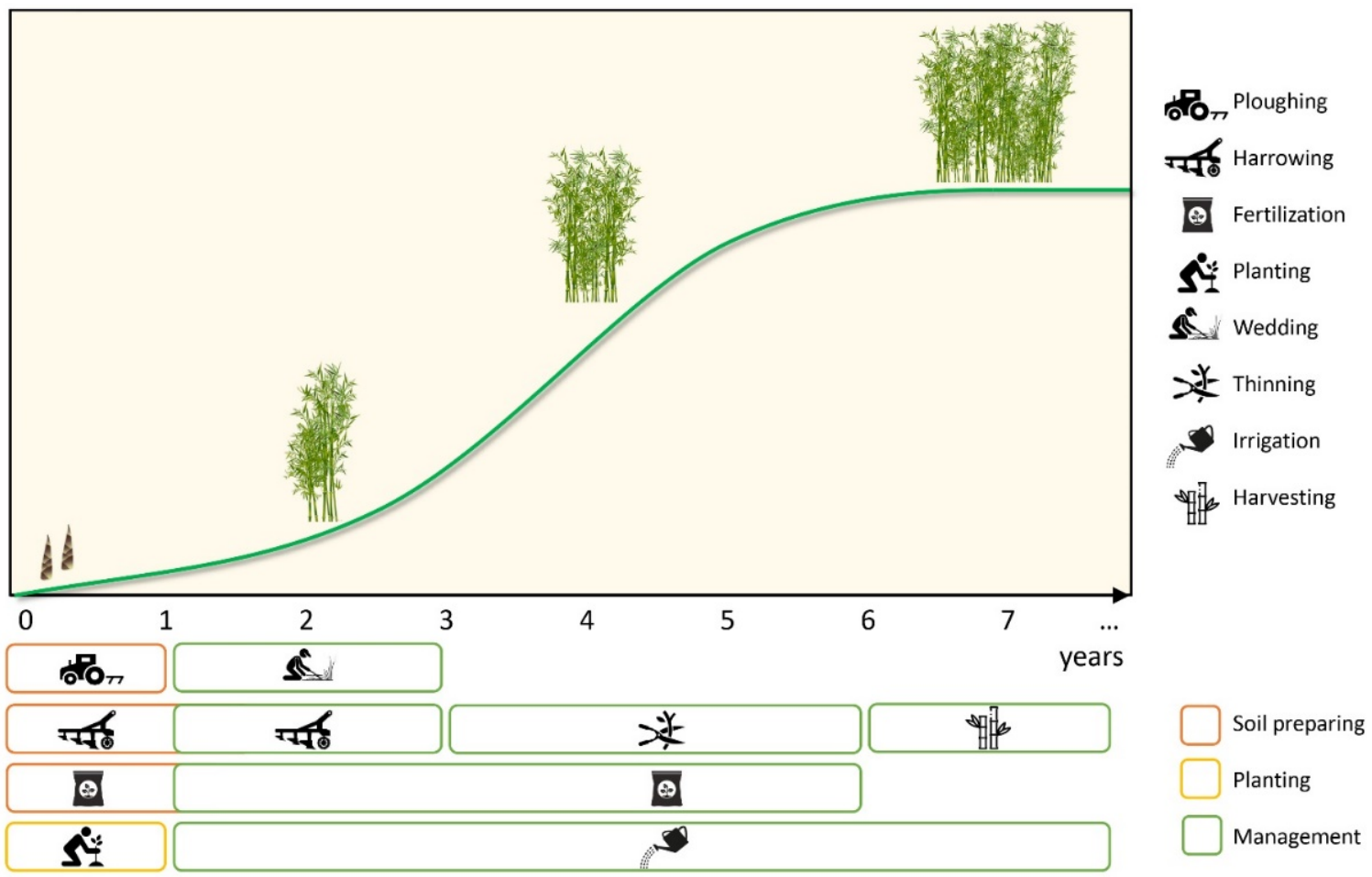

Figure 2. Time allocation of processes and agricultural activities in the field for Moso bamboo cultivations.

The plants, usually supplied in plastic pots, were planted in rows about $3.5 \mathrm{~m}$ long and spaced $1.5 \mathrm{~m}$ from each other. Phillostachyis bamboo species are known to be invasive and this was thus an important aspect to consider when preparing the field, as the rhizomes could quickly invade neighboring lands. To address the problem of the invasiveness of bamboo, a perimeter trench $60 \mathrm{~cm}$ deep and $60 \mathrm{~cm}$ wide was needed to keep the ditch clean. The annual water requirement for irrigation is about $1000-2000 \mathrm{~m}^{3} / \mathrm{ha}$ and this is assumed to be a recurrent activity over the whole lifespan of the plantation.

Contrarily, fertilization for soil enrichment is a key input that is assumed to be performed over the first six years, during which the plantation grows to achieve full maturation. The last process, which is repeated yearly up to maturation, is thinning. Usually, a chainsaw or a disc brush cutter are used to clear-cut the base of the culms and remove the under-grown bamboo canes. Most of the energy-intensive processes are assumed to be performed during the first six years (maturation period), while harvesting takes place from full maturation to the end of life. All the specific processes used for the inventory in the ecoinvent dataset are reported in Table A1 in Appendix A.

\subsection{Bio-Composite Fabrication Protocol}

The production process of MycoBamboo can be summarized in three different steps: (i) inoculation, (ii) incubation, and (iii) deactivation. There is no general agreement on 
the timings and actions of these main three steps $[39,40]$. Therefore, a specific protocol of growth was proposed at the lab scale, resulting from preliminary experiments, as the state of the art (Figure 3).

\begin{tabular}{|l|l|l|l|l|}
\hline day 0 & day 1 & day 6 & day 12 & day 18 \\
\hline Inoculation & \multicolumn{3}{|l|}{ Incubation } \\
\hline
\end{tabular}

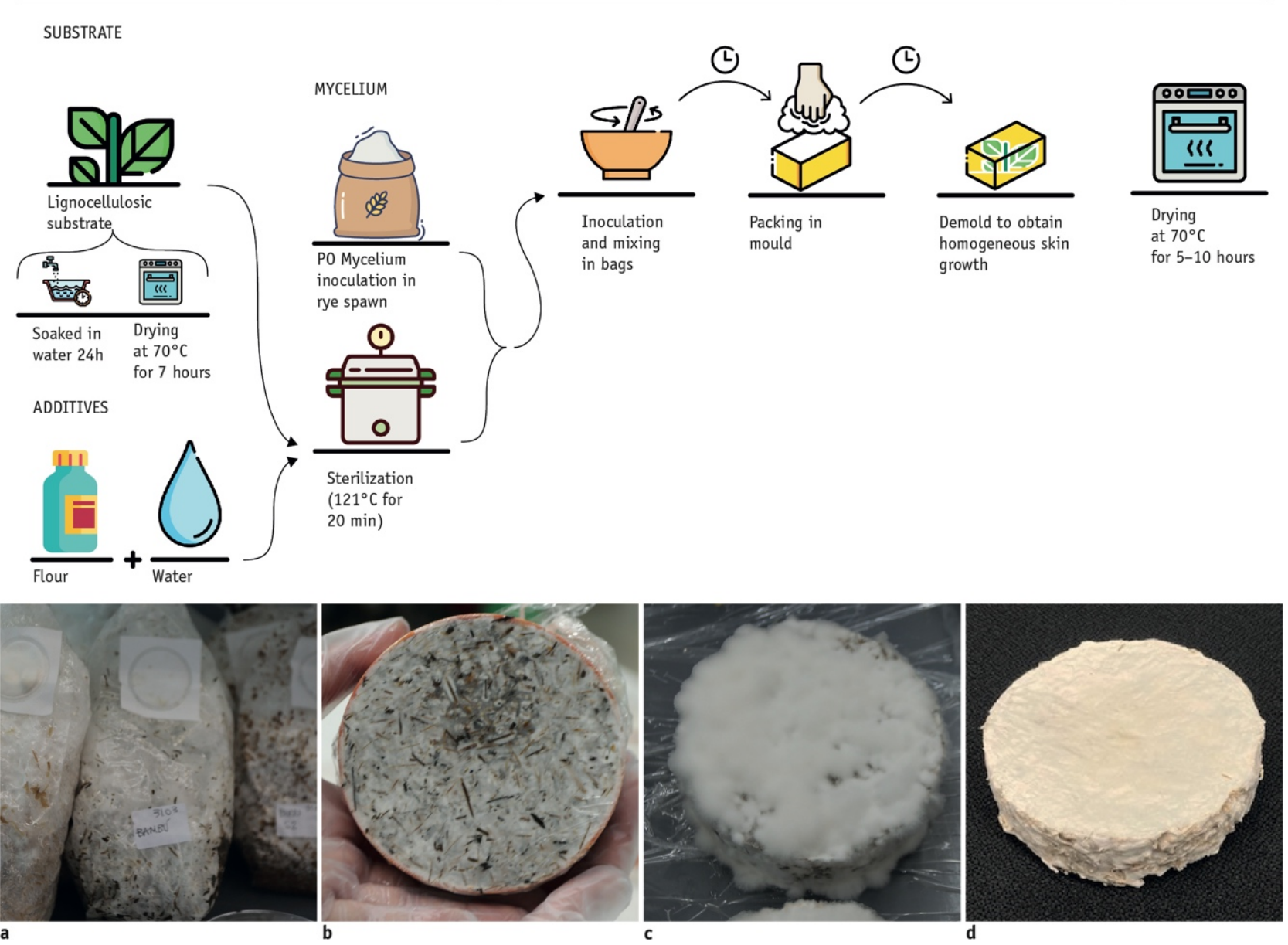

Figure 3. Schematic diagram of the production process of the mycelium bio-composite (MycoBamboo). (a) The starting of the incubation period after the inoculation and mixing steps; (b) shows the bio-composite once packed in molds; (c) the bio-composite that has been demolded; (d) the MycoBamboo once deactivated.

In the first step, the lignocellulosic substrate, a mix of bamboo (with particle sizes of $15 \mathrm{~mm}$ maximum) was prepared to guarantee the proper fabrication of the final product. Initially, the substrate was soaked in water for $24 \mathrm{~h}$ to be hydrated, and then dried for $7 \mathrm{~h}$. Later, the bamboo particles were homogenized in terms of length with a kitchen blender for a duration of $20 \mathrm{~s}$. Once the substrate was properly prepared, it was sterilized to remove the microbial competition of existing bacteria and microorganisms already present in the material. The sterilization was performed in a high-pressure autoclave up to a temperature of $121^{\circ} \mathrm{C}$ and a pressure of $100 \mathrm{kPa}$ for a duration of $20 \mathrm{~min}$.

Then, it was possible to proceed with the mycelium inoculation by introducing and dispersing $15 \mathrm{wt}$.\% of fungal biomass into the plastic bags containing the pressurized feedstock. A commercial rye spawn ready-mix with Pleurotus Ostreatus spores was used. The inoculated substrate was stored in a controlled dark environment for the incubation, with a constant temperature of $25{ }^{\circ} \mathrm{C}$ and $90 \%$ relative humidity. The incubation time depends on different factors, e.g., type of fungi, substrate, shape and size of the sample, 
application, etc. Here, three different phases were distinguished according to the growth of the mycelium: the first growing period, which took place in the plastic bag for 6 days; the second one, wherein the composite was placed in the mold for an additional 6 days to provide the desired shape to the material; the last phase, wherein the material was removed from the mold for the last 6 days to solidify the outer skin. To shape the samples, a PVC mold was selected with the assumption that it could be reused after a proper sterilization for 25 cycles. Finally, the sample was heat-treated in an electric oven at $70{ }^{\circ} \mathrm{C}$ for seven hours to stop the growing process and dehydrate the composite. The thermal conductivity of the dried samples was measured though the Transient Plane Source (TPS) dynamic technique, according to the ISO 22007-2:2015 [41] standard. All processes used in the ecoinvent dataset are reported in Table A1 in Appendix A.

\subsection{Application for Retrofitting Existing Building Wall}

The MycoBamboo solution assessed at lab scale was finally up-scaled to a building component as a retrofitting solution for existing facades. For this specific application, $1 \mathrm{~m}^{2}$ of renovated façade was assumed as FU, and the context of a southern dry Mediterranean region was selected to investigate the climate mitigation potential. A targeted U-value of $0.5 \mathrm{~W} / \mathrm{m}^{2} \mathrm{~K}$ was considered [42] and the solution was compared with other bio-based and non-bio-bases retrofit alternatives. In Figure 4, the methodological steps for the comparison of the reference building wall applications and the outputs are depicted. A masonry wall composed of $20 \mathrm{~cm}$ of hollow clay bricks with ETICS was assumed as the representative archetype. Fossil-based and bio-based insulation typologies were assessed here, namely, five bio-based alternatives (straw fibers (STR), cotton stalks (COT), expanded cork (COR), kenaf fibers (KEN), and bamboo particles bonded with mycelium), and another fossil-based one, namely, EPS. With this information, it was possible to calculate the required thickness of the insulation composite to comply with the defined U-value and the related emissions and storage uptake for each layer of the two walls.
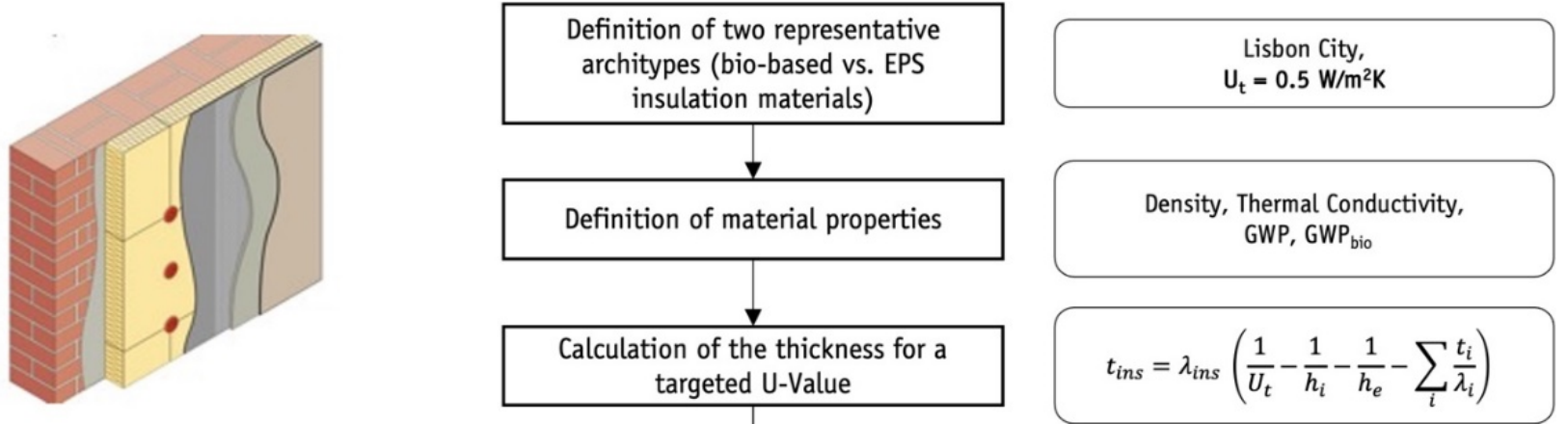

$$
t_{\text {ins }}=\lambda_{\text {ins }}\left(\frac{1}{U_{t}}-\frac{1}{h_{i}}-\frac{1}{h_{e}}-\sum_{i} \frac{t_{i}}{\lambda_{i}}\right)
$$

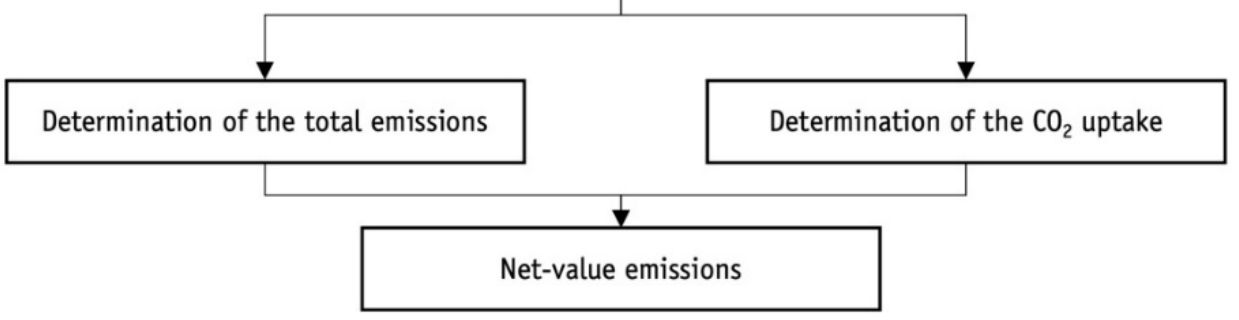

Figure 4. Methodological approach for the comparative carbon footprint assessment of a $1 \mathrm{~m}^{2}$ renovated wall.

\subsection{Life Cycle Assesment}

\subsubsection{System Boundaries and Functional Unit}

Life-cycle assessment (LCA) is a well-established methodology for providing a comprehensive analysis of the environmental impacts of a product over its life cycle. In this study, a cradle-to-gate LCA (mod. A1-3) was performed according to EN 15804 and ISO 14067, 
with the exceptional inclusion of biogenic $\mathrm{CO}_{2}$ emissions to determine the benefit derived from carbon storage and delayed emissions at EoL. Two different functional units were defined for the two systems: 1 circular sample of MycoBamboo with $\phi=100 \mathrm{~mm}, \mathrm{~h}=30 \mathrm{~mm}$, and $1 \mathrm{~m}^{2}$ of renovated wall with a $\mathrm{U}$-value equal to $0.05 \mathrm{~W} / \mathrm{m}^{2} \mathrm{~K}$. Concerning the cultivation of bamboo, the outputs refer to 1 hectare of cultivated land. The weight of each MycoBamboo sample was around $33 \mathrm{~g}$, with a volumetric mass equal to $229 \mathrm{~kg} / \mathrm{m}^{3}$. The boundaries of the system for MycoBamboo production are depicted in Figure 5.

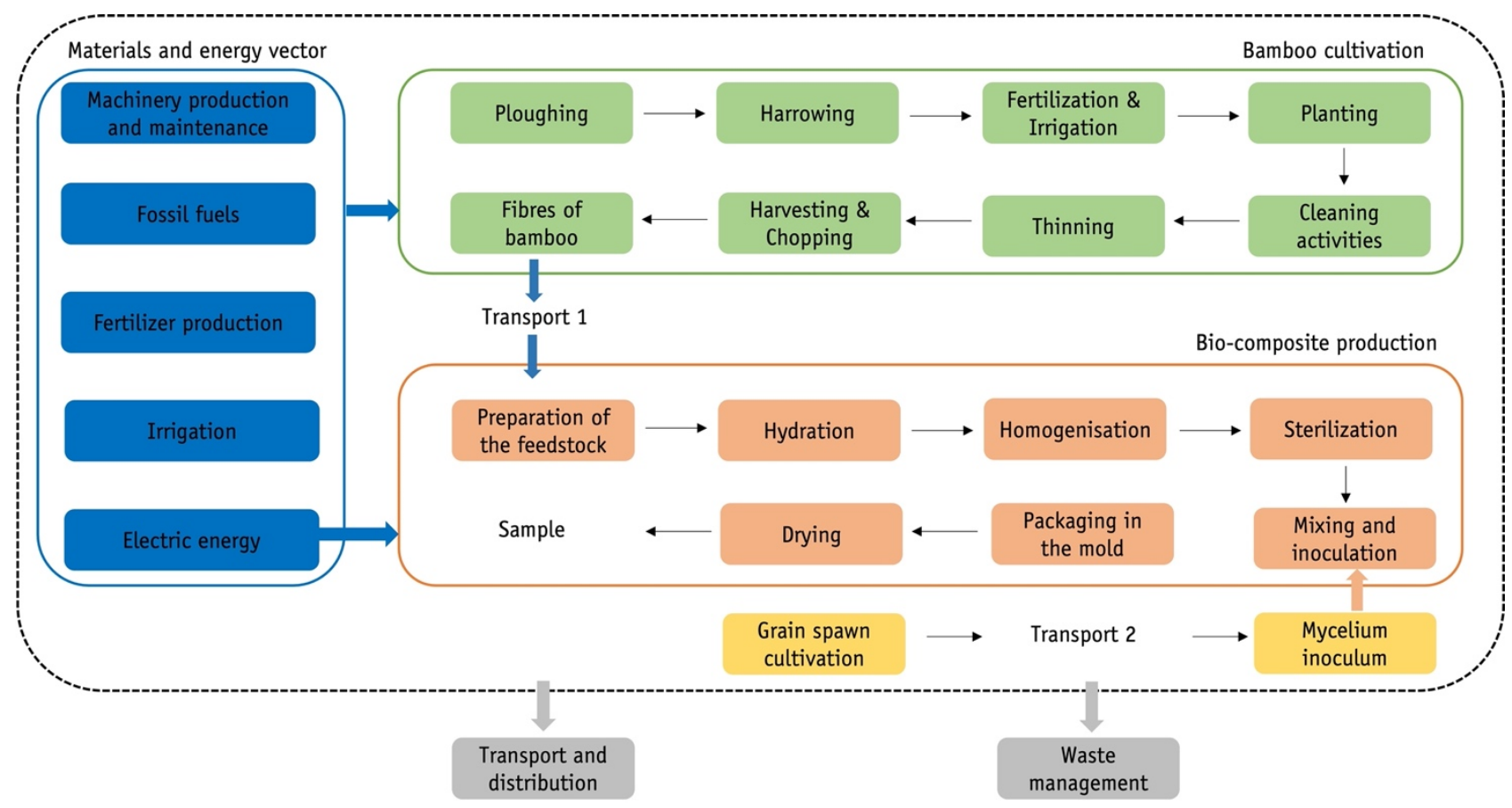

Figure 5. Flowchart of the bamboo-mycelium composite and system boundaries.

\subsubsection{Data Quality}

The LCA distinguishes primary and secondary data. Primary data were used for inputs directly linked to bamboo cultivation and laboratory protocol. For the bamboo cultivation, data were sourced from a garden center Onlymoso [35], a farm dealing with the production of bamboo mother plants. For the production of MycoBamboo, data were collected at MaBa.SAPERLab [43]. Secondary data were taken from the ecoinvent dataset, and we referred to the literature for non-represented data.

\subsubsection{Allocation Method}

The cultivation of bamboo can generate different co-products and by-products. To maximize the environmental benefit, $90 \%$ of the yield was assumed to be used for suppling biomass for structural laminated products, while the remaining $10 \%$ was considered a byproduct that can be chopped and used as a substrate for MycoBamboo production. Bamboo shoot harvesting for the food market was not considered as a business option since the aim of cultivation management is to maximize the carbon storage along the whole value chain. The total annual harvested biomass corresponds to 75 tons for the sixth and seventh years and 100 ton from eighth year on. An additional annual biomass flow of roughly 10 tons at years three, four and five is assumed as a result of thinning, since all removed non-developed culms can be chopped in the field and used to supply the substrate for MycoBamboo production.

According to ISO 14040 [44], a physical relationship should be preferred for impact allocation. However, when a physical relationship cannot be applied, an economic allocation can be used. Since the different co-products have very different market values, in this study, both mass and economic allocation were used. The variability in the co-products' value is 
generally very high and difficult to predict. Concerning the bamboo products, economic value was assumed as the allocation driver, namely, $99 \%$ of the value for mature bamboo culms and $1 \%$ of the value for non-developed culms.

\subsubsection{LCI Inventory Assessment}

Inputs from bamboo cultivation, in particular fuel consumption during soil preparing and management, were estimated by direct site measurements. Particularly, for each unit process, the use of New Holland machinery (T5000 Tractor series) was considered. Then, depending on the type of equipment used for the required process and the duration of the process, the corresponding fuel consumption was calculated. Specific fuel consumptions for bamboo growing processes are summarized Table 1, while fertilizer consumption and planted seeds are collected in Table 2. All data used to model agriculture processes and the consumption of fertilizers were taken from the ecoinvent dataset. The data used to model transportation can be found in Table A2 in Appendix A.

Table 1. Fuel consumptions during the different processes for bamboo cultivation.

\begin{tabular}{cccc}
\hline Process Unit & Fuel & Tractor Use & Tractor Consumption \\
\hline Ploughing & $(\mathrm{kg} / \mathrm{h})$ & $(\mathrm{h} / \mathrm{ha})$ & $(\mathrm{kg})$ \\
\hline Harrowing-1 & 14.63 & 5 & 36.56 \\
\hline Fertilization-1 & 14.63 & 2.5 & 8.78 \\
\hline Harrowing-2 & 8.78 & 1 & 29.26 \\
\hline Thinning & 14.63 & 2 & 10 \\
\hline Harvesting & 1.00 & 10 & $37.80 / 44.10$ \\
\hline
\end{tabular}

Table 2. Amounts of fertilizers and seed needed for the cultivation of 1 ha of field.

\begin{tabular}{cc}
\hline Input & Quantity \\
\hline & $(\mathrm{kg})$ \\
\hline Ammonium nitrate phosphate & 160 \\
\hline Potassium chloride & 80 \\
\hline Phosphor & 60 \\
\hline Seeds & 50 \\
\hline
\end{tabular}

Since not enough information was available for modeling the small bamboo plants supplied in the field for the planting phase, the direct plantation of the seeds was assumed, as well as the supply of plastic vases for transportation. The amount of seeds needed was assumed to be $50 \mathrm{~kg}$ per hectare of field. The water requirement for the bamboo plants varies during the life cycle of the plantation. In the first seven years, during maturation, it is around $1500 \mathrm{~m}^{3} / \mathrm{ha}$. Then, from the eighth year, the required amount drops to around $750 \mathrm{~m}^{3} / \mathrm{h}$. These values were directly collected on site and are highly sensitive to monthly rainfall rates. A drip irrigation system was assumed with an average flow rate of $411 / \mathrm{h}$. Assuming 1200 plants per hectare, an average capacity of $4.8 \mathrm{~m}^{3} /$ ha per hour was obtained. Depending on the dimension of the field and the sector that needs to be irrigated, a pump with a minimum power of $1 \mathrm{hp}$ is needed. In this case, a pump with an average value of $4 \mathrm{hp}(2.94 \mathrm{~kW})$ was considered.

The energy consumption of the processes carried out in the laboratory was directly measured though an electricity meter. The resulting energy consumption and the duration of each unit process, as well as the reference quantity of material processed with such energy usage, are summarized in Table 3. Moreover, two hypotheses of energy sources 
were validated to estimate the sensitivity of the carbon footprint according to the type of energy used: (i) electricity fully supplied by the grid based on the IT energy mix, and (ii) electricity from $100 \%$ onsite renewable production.

Table 3. Amount of energy consumption during the bio-composite production.

\begin{tabular}{cccc}
\hline Process Unit & Quantity & Duration & Energy Consumption \\
\hline Homogenization & & $(\mathrm{h})$ & $(\mathrm{kWh})$ \\
\hline Sterilization & 0.2 bags & 0.0056 & 0.0056 \\
\hline Drying & 3 bags & 0.6670 & 0.205 \\
\hline
\end{tabular}

\subsubsection{Assessment Method for Carbon Footprint and Biogenic Carbon Accounting}

The Net-GWP of construction materials is assumed as the sum of the GWP at 100 years, calculated according to the IPCC 2013 method, and the related GWP from biogenic $\mathrm{CO}_{2}$ emissions (GWPbio index) at the EoL of MycoBamboo, calculated though a dLCA for a fixed storage period ( 30 or 60 years), a rotation period of 6 years, and a horizon time of 100 years, according to Guest et al. [45].

The $\mathrm{CO}_{2}$ storage of this novel bio-based insulation composite was determined according to the following Equation (1):

$$
\mathrm{CO}_{2, \text { storage }}=\rho_{0} \cdot \mathrm{CC} \cdot B C \cdot 3.67[\mathrm{~kg} \mathrm{CO} / \mathrm{kg}]
$$

where:

- $\quad \rho_{0}$ is the dry density of the material in $\mathrm{kg} / \mathrm{m}^{3}$, namely, $229 \mathrm{~kg} / \mathrm{m}^{3}$;

- $\quad C C$ is the carbon content of the bamboo particles, namely, $54 \%$ [9];

- $\quad B C$ is the biomass content of the finished composite, which corresponds to $100 \%$;

- $\quad 3.67$ is the molar weight ratio between $\mathrm{CO}_{2}$ and $\mathrm{C}$ [11].

Besides the quantification of the $\mathrm{CO}_{2}$ content, it was also necessary to consider the biogenic $\mathrm{CO}_{2}$ emissions under the EoL scenario according to the different waste treatments. The $\mathrm{CO}_{2}$ emissions due to the selected waste treatments should be determined and included as input in the dynamic LCA model. As a matter of fact, three different EoL scenarios were first considered, namely, incineration, sanitary landfill, and anaerobic composting (Figure 6). Since waste treatment with sanitary landfill and incineration in the EU should be avoided [46-48], these options were discarded, and only anaerobic digestion with biogas production was taken into account.
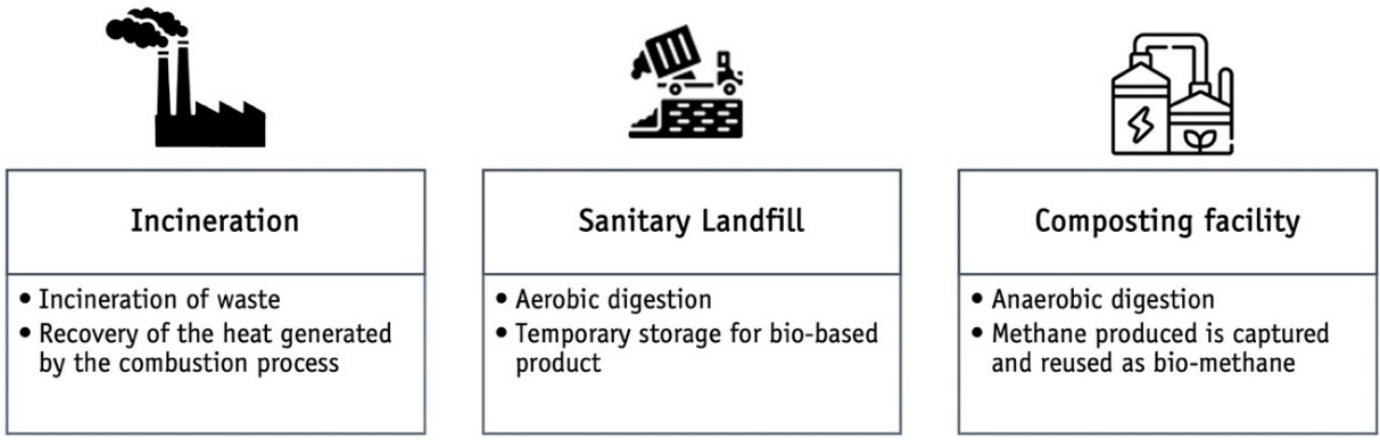

Figure 6. End-of-life scenarios for the bio-composite.

To define the amount of biogenic $\mathrm{CO}_{2}$ emitted in the air during the anaerobic composting of MycoBamboo, the methane production of straw was taken as a reference [49] to determine the flow direction of the organic carbon in the anaerobic bio-conversion process. In this case, a high percentage of carbon (41.4\%) is usually fully converted or degraded 
into inorganic carbon. In addition, most carbon is converted to $\mathrm{CO}_{2}$ and $\mathrm{HCO}_{3}(32.8 \%)$, followed by methane $(18.6 \%)$, which is captured by a collecting infrastructure and its direct emission is avoided. These corresponding GHG emissions were first allocated to 1 sample and then converted to $1 \mathrm{~kg}$ of product. With the data collected for the $\mathrm{CO}_{2}$ storage and biogenic $\mathrm{CO}_{2}$ emissions at EoL, a specific $\mathrm{GWP}_{\text {bio }}$ index for MycoBamboo was computed though the "DynCO2" calculation tool [50]. Time-dependent $\mathrm{CO}_{2}$ pulses are reported in Table A3 in Appendix A. The storage period for the calculation was assumed to be equal to the product's service life. In this case, two values of reference service life were assumed for a typical installation of bio-based materials as ETICS, namely, 30 years [51] and 60 years [52].

\section{Results}

\subsection{Carbon Footprint of One Sample of MycoBamboo}

The results of the carbon footprint calculation were evaluated for the two alternative storage periods- 30 years vs 60 years-according to the EoL scenario assumed. GWPbio is included as "Biogenic $\mathrm{CO}_{2}$ " by assuming that the same amount of carbon stored in the bamboo particles used for MycoBamboo processing is regenerated within seven years after production in the bamboo plantation.

In the column chart of Figure 7, the resulting GWPs for the two reference service lives are compared. Despite the negative GWP values for biogenic $\mathrm{CO}_{2}, 54$ and $49 \mathrm{gCO}_{2 \text {-eq }} /$ sample for the two reference scenarios, respectively, the resulting Net-GWP in both cases is positive, at respectively 30 and $36 \mathrm{gCO}_{2 \text {-eq }}$ /sample with storage for 60 and 30 years. The GWP balance is negatively affected by laboratory-scale processes, which, contrarily to up-scaled industrial production, are not optimized to reduce electricity overloads.

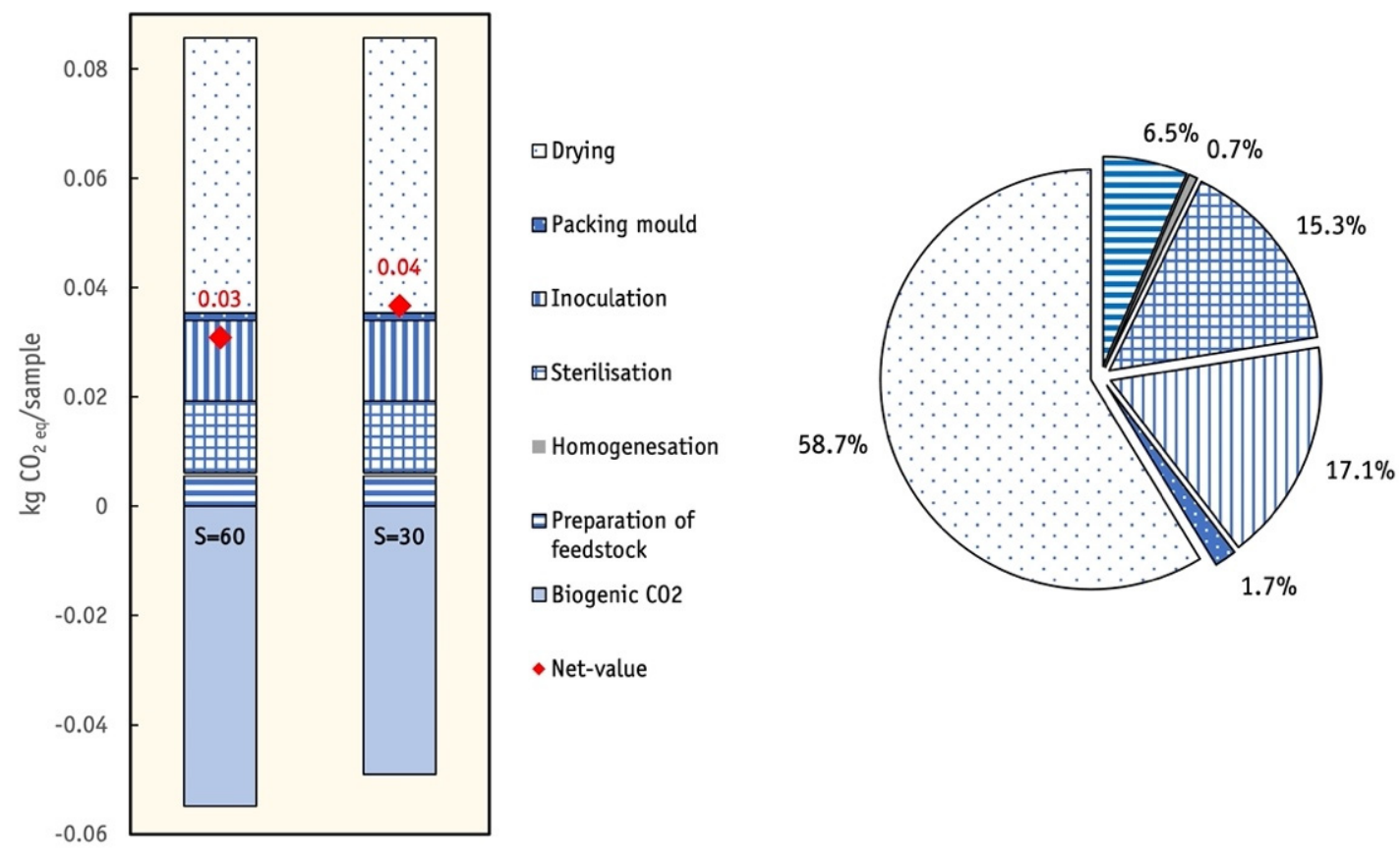

Figure 7. Global Warming Potential (GWP) of MycoBamboo for each production process (A1-3). On the left, a comparison of results for the two storage scenarios, 60 and 30 years. On the right, the percentage contribution of each production process to the GWP.

In the pie chart of Figure 7, a detailed comparison of the incidence of each process for one MycoBamboo sample is shown. Drying is the process with the highest effect on GWP, at nearly $60 \%$ of the total, due to the high energy intensity of the oven and the duration of the deactivation process of mycelium. Inoculation affects the GWP process to the second highest degree $(17 \%)$, wherein the production of the grain spawn plays an important role. The use of the autoclave for $20 \mathrm{~min}$ for the sterilization of the feedstock has a non-negligible 
impact on the GWP, with an incidence of around 15\%. All other processes have a marginal influence, including feedstock preparation, where cultivation processes are considered for the substrate needed. A network flow representation of the process contributing to GWP is reported in Figure A1 in Appendix A.

\subsection{Carbon Footprint of $1 \mathrm{~m}^{2}$ of Renovated Wall}

In this paragraph, the resulting GWPs of the building wall application are presented. In Table 4, the insulation thicknesses for six different categories of insulation used as ETICS, both bio-based and non-bio-based, are reported to comply with the targeted U-value for renovated walls in southern dry regions. The required thickness for the bio-composites is $9 \mathrm{~cm}$ for MycoBamboo (MYC), while a range between 5 and $6 \mathrm{~cm}$ is requested for alternative bio-based solutions, namely, straw (STR), cotton stalks (COT), expanded cork $(\mathrm{COR})$ and kenaf $(\mathrm{KEN})$, and $5 \mathrm{~cm}$ is required for expanded polystyrene (EPS). The resulting amount of material per $\mathrm{m}^{2}$ is much larger than with other bio-based alternatives, since the thermal conductivity measured on laboratory-scale samples is slightly higher than that of the alternatives.

Table 4. Material inventory for the six insulation alternatives for exterior wall renovation-five bio-based and one non-bio-based.

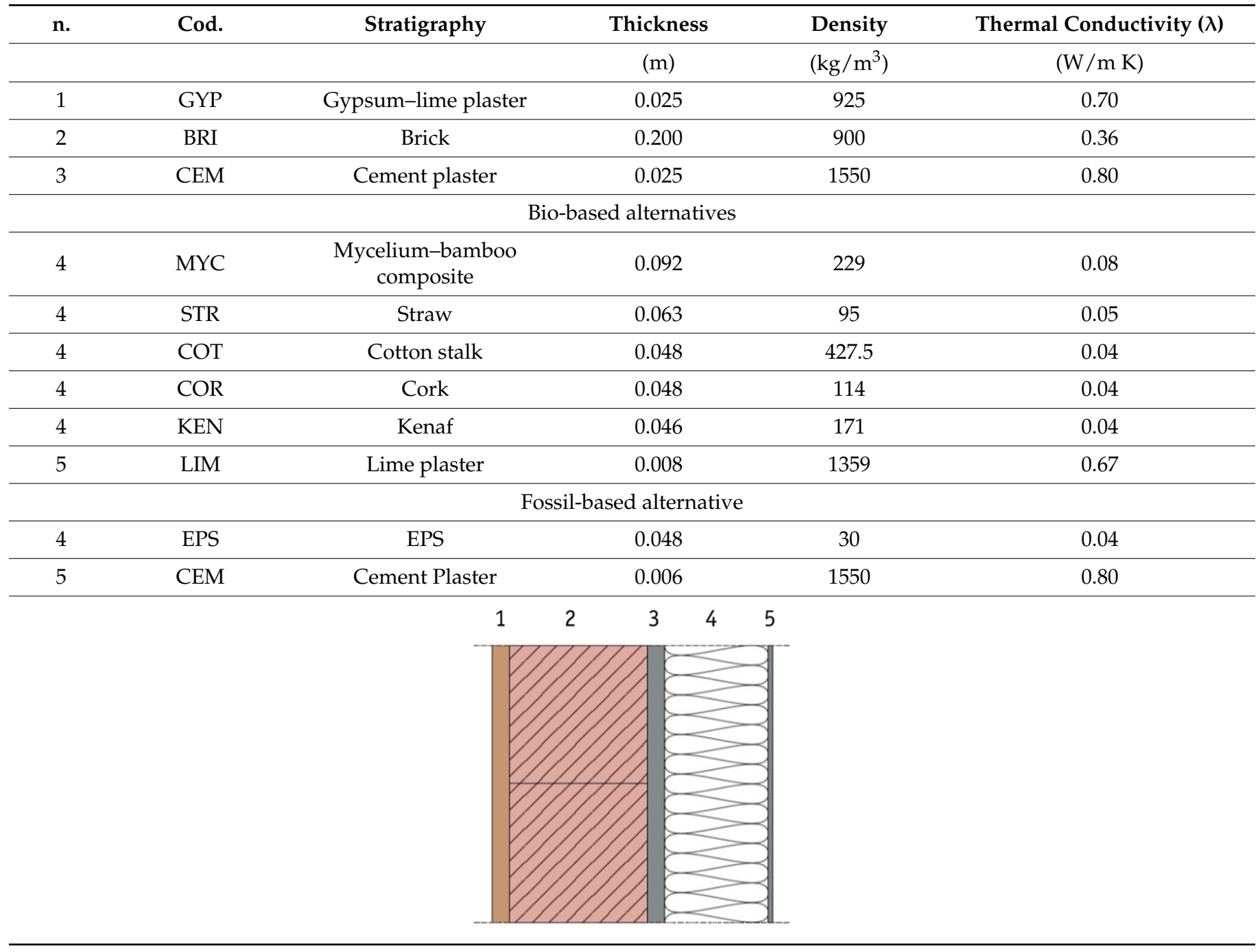


The Net-GWP for each alternative solution, calculated for a storage period of 60 years ( $S=60$ years), is depicted in Figure 8, with the two alternative hypotheses for MycoBamboo regarding the electricity source. The achieved results show that when up-scaling the process from laboratory- to building component-scale, with electricity provided by the national grid, MycoBamboo accounted for a slightly higher GWP compared with other alternatives. Even if the high carbon storage contributes to a negative GWP, which is nearly 2.6 times that of COT due to the high volumetric mass and the extra material needed to provide the same U-value, it is not sufficient to compensate for the high fossil-driven GWP. Under these assumptions, the most promising bio-based alternative is COT, which accounted for a Net-GWP 32\% lower than MYC. Contrarily, when the electricity is provided by a $100 \%$ renewable source, the fossil-driven GWP of MYC can be reduced by $45 \%$, which is $20 \%$ lower than COT and 36\% lower than EPS.

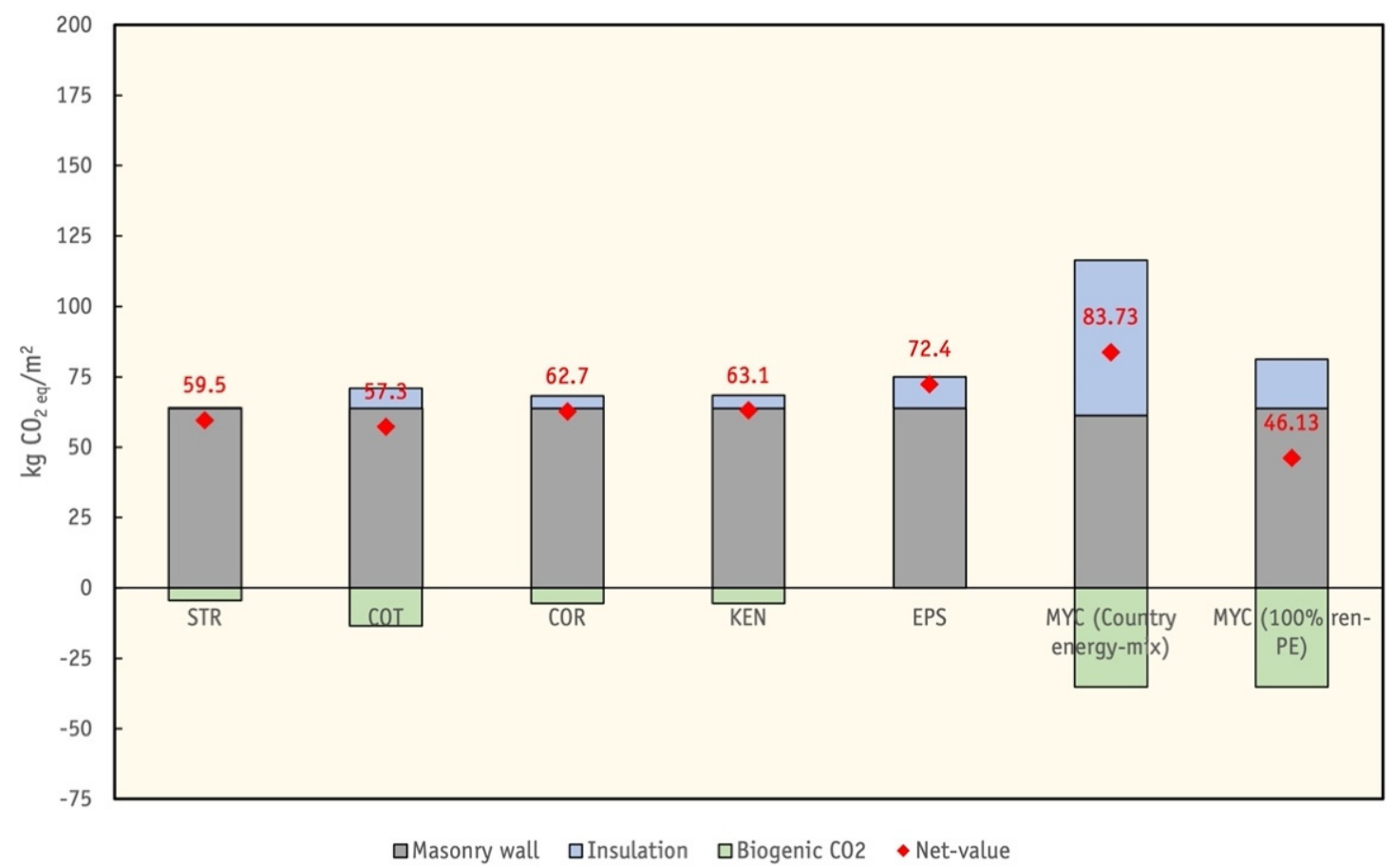

Figure 8. GWP of a renovated wall with six insulation alternatives and a storage period (S) of 60 years. The emissions of the existing masonry wall are shown in gray. The emissions of the production of the insulating materials are shown in blue. In green: the stored biogenic $\mathrm{CO}_{2}$. The red indicator represents the Net-GWP.

If a technical replacement of the ETICS after 30 years $(S=30)$ is considered for each alternative (Figure 9), with the substitution of the thermal insulation and the exterior mineral render, the incremental difference between the Net-GWP of MYC and its alternatives tends to increase compared to the first scenario with $S=60$. Under this scenario, STR is the solution with the lowest Net-GWP due to its very low GHG emissions during manufacturing, which are $43 \%$ lower than those of MYC. Additionally, in this case, if a $100 \%$ renewable electricity source is considered, MYC achieves the lowest Net-GWP, with a reduction of $64 \%$ compared to the current option using an energy mix. 


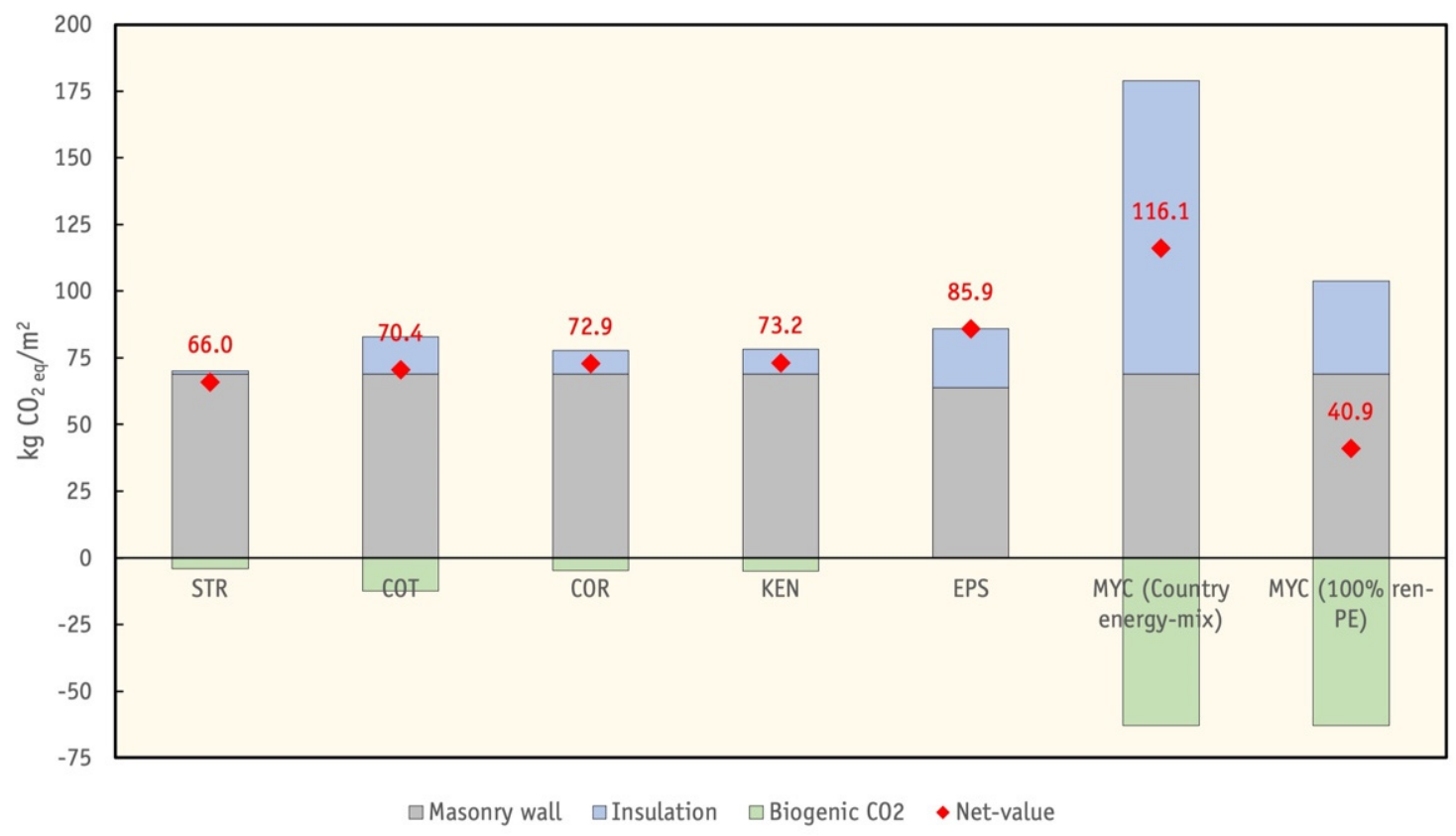

Figure 9. Net-value emissions of the wall for the 30-year storage period.

\subsection{Processes Incidence and Alternative Energy Scenarios}

The production of a sample of MycoBamboo contributes $86 \mathrm{gCO}_{2 \text {-eq }}$ of emissions, which is mostly caused by the drying process (Figure 10). The deactivation of the fungus is the most energy-intensive activity, since it requires the continuous use of an electric oven over $7 \mathrm{~h}$ at $70{ }^{\circ} \mathrm{C}$, with a consequential contribution of $58 \%$ to the total carbon emissions,

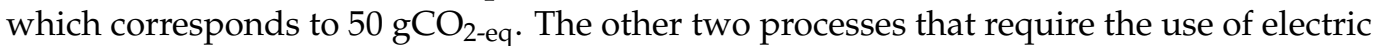
energy are sterilization and homogenization, which have a lower impact due to the minimal duration of the activities.
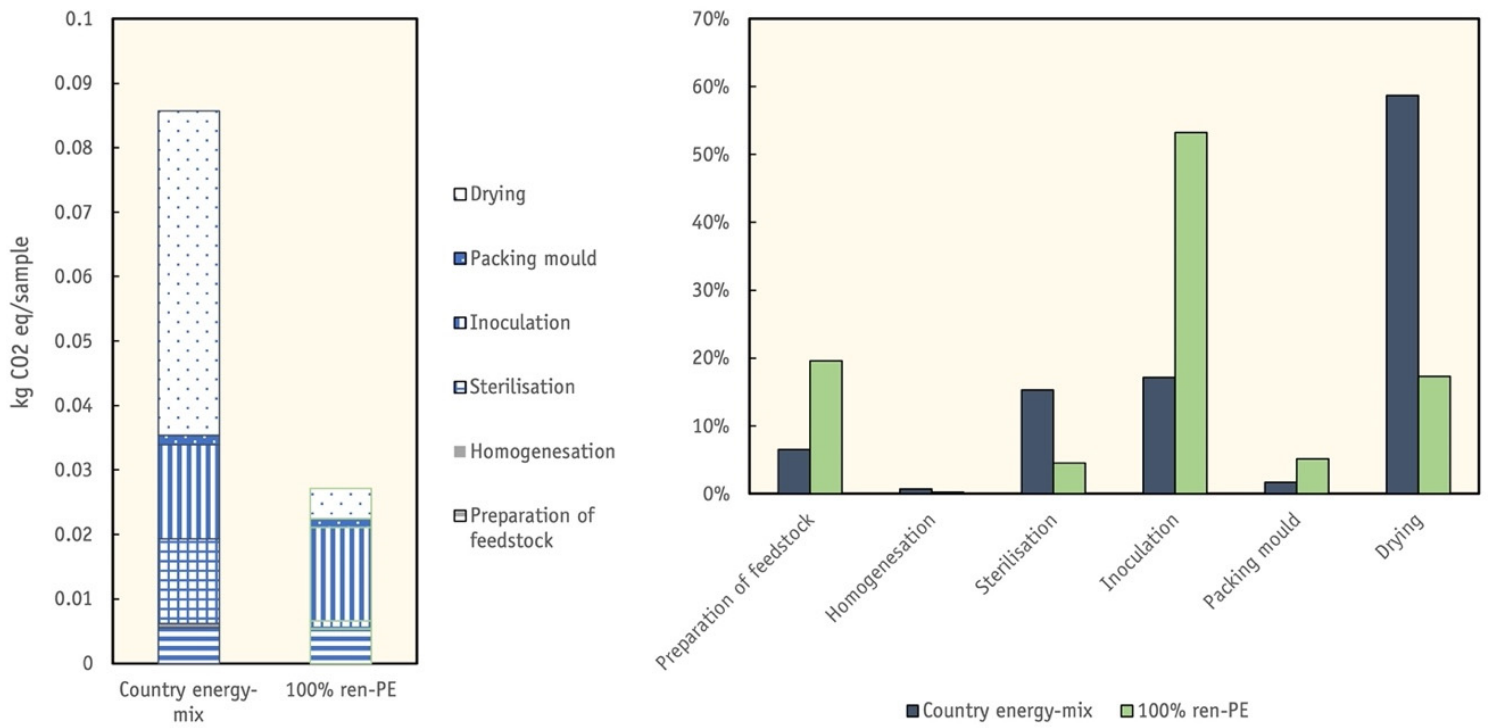

Figure 10. Processes' contribution to GWP for the laboratory fabrication of one MycoBamboo sample under the two alternative energy scenarios. On the left, comparison between IT energy mix and a $100 \%$ renewable PE. On the right, percentage of incidence of the main processes under the two energy scenarios.

Figure 10 shows a comparison between the two electricity scenarios, IT energy mix and $100 \%$ renewable PE. When a fully renewable energy source is applied for electricity 
supply, the overall GWP per sample is three-fold lower than in the IT energy mix scenario,

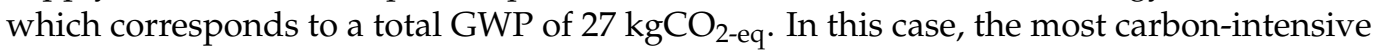
processes are inoculation, with a 53\% contribution, and the preparation of the feedstock, with a $20 \%$ contribution, while the deactivation drops with a contribution equal to $17 \%$,

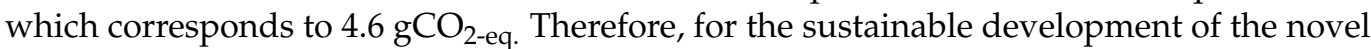
MycoBamboo under industrial up-scale, the energy source plays an important role in the mitigation of climate change.

\section{Discussion}

This study has investigated the carbon footprint of MycoBamboo, a novel product that can be used to insulate buildings. Considering the lack of information in the literature about the sustainability of mycelium composites, the analysis carried out at the laboratory scale allowed us to investigate the carbon emissions of the different production stages and determine the field of improvement for future carbon saving. However, as shown in the results section, the LCA performed at the laboratory scale for one sample may not be representative of large-scale industrial implementation for the manufacturing of building components. In fact, the use of energy, as well as the transportation of materials and equipment, is not optimized at laboratory scale, and the carbon emissions caused by material processing can be drastically reduced at industrial scale. However, in the results obtained, MycoBamboo showed relatively low carbon emissions compared to alternative bio-based insulation solutions due to its high content of biological wastes and the lack of synthetic binders. Even if the substrate has a low effect on the total carbon emissions, by using bamboo as a substrate, it can store a large amount of biogenic carbon and valorize agricultural wastes according to the principles of the circular economy. Despite these very promising and encouraging results, there are still some aspects that need to be further investigated, since they may affect the carbon footprint of the product at a large scale. In particular, the EoL requires additional investigation. For this study, the lignocellulose content was assumed from the literature to be identical to that of straw. However, a direct measurement would provide the actual carbon content in the product, and consequently the emissions at the EoL. Moreover, alternative solutions employed to reduce the energy intensity of drying are required, as its contribution to carbon emission is relevant when the current country-wide energy mix is considered for electricity supply. Besides the use of renewable energy, which share is assumed to drastically increase in the next few decades in EU, alternative low-energy technologies to quickly deactivate fungal growth are needed over the transition period until domestic electricity can become fully carbon-free. Lastly, fire safety should be further examined to understand the necessity of adding (or not) fire retardants/coatings, or of developing design strategies [17]. However, fire resistance is one of the main issues that is preventing the application of bio-based materials in ETICS or ventilated facades for multi-story buildings [53].

\section{Conclusions}

The lack of information on already-industrialized products led this investigation to assess the carbon footprint of the novel MycoBamboo composite fabricated at the laboratory scale. The focus of the analysis provides different levels of insight, from the carbon storage potential and the effects of the origin of the electricity used in the process, up to a comparison with alternative insulation solutions.

The findings demonstrate that:

- Despite the negative GWP values of biogenic $\mathrm{CO}_{2}$-respectively, 54 and $49 \mathrm{~g} \mathrm{CO}_{2 \text {-eq } / ~}$ sample for the two reference scenarios - the final Net-GWP is positive for both replacement scenarios-respectively 30 and $36 \mathrm{gCO}_{2 \text {-eq }} /$ sample-for storage for 60 and 30 years;

- the technical replacement scenarios have an influence on the final Net-GWP values, and a longer storage period should be preferred to more frequent insulation substitutions to maximize carbon sequestration in building facades; 
- even if laboratory-scale processes are not optimized to reduce electricity overloads, contrarily to an up-scaled industrial production, this work provides useful insight into the carbon emissions of the different production stages, and determines the sphere of influence for future carbon saving;

- to achieve the targeted U-value for renovated walls in southern dry regions, the thicknesses required for MycoBamboo are higher $(9 \mathrm{~cm})$ with respect to alternative biobased and non-bio-based solution, which range from 5 to $6 \mathrm{~cm}$;

- to compete with alternative insulation solutions and for a sustainable industrial upscaling of the novel MycoBamboo material, the energy source and the deactivation strategy play important roles in lowering the Net-GWP values;

- future studies should be focused on creating a specific EoL for these bio-composites, finding alternative drying solutions and addressing the fire safety requirements.

Author Contributions: Conceptualization, F.P. and O.B.C.; methodology, P.M.; software, P.M.; validation, G.H., F.P., I.P. and S.C.; formal analysis, G.H.; investigation, P.M.; resources, I.P.; data curation, P.M.; writing — original draft preparation, O.B.C.; writing—review and editing, F.P.; visualization, O.B.C.; supervision, G.H.; project administration, F.P. All authors have read and agreed to the published version of the manuscript.

Funding: This research received no external funding.

Institutional Review Board Statement: Not applicable.

Informed Consent Statement: Not applicable.

Acknowledgments: The authors would like to thank the Consorzio Bambù Italia soc. consortile a.r.l. and OnlyMoso for the technical support provided for data collection and knowledge on bamboo cultivation processes. Particular gratitude is expressed to Fabrizio Pecci, CEO of the consortium, and Damiano Pagnini for the constant support during the project development and laboratory activities. Moreover, we want to acknowledge the master's students of Politecnico di Milano Luca Ficarelli and Marco Lenzi for their precious contribution during the mycelium fabrication protocol definition stage.

Conflicts of Interest: The authors declare no conflict of interest.

\section{Appendix A}

Table A1. Ecoinvent processes used for the GWP calculation of each material in the SimaPro software.

\begin{tabular}{|c|c|c|c|c|}
\hline Process & Material and Fuels & Energy Consumption & Amount & Unit \\
\hline \multicolumn{5}{|c|}{ Bamboo Cultivation for ha and 100 Years } \\
\hline Ploughing & & & 1 & ha \\
\hline & Tractor & & 1.55 & $\mathrm{~kg}$ \\
\hline & Agricultural machinery & & 2.16 & $\mathrm{~kg}$ \\
\hline & Shed & & 0.00801 & $\mathrm{~kg}$ \\
\hline & Diesel & & 73.13 & $\mathrm{~kg}$ \\
\hline Harrowing & & & 1 & ha \\
\hline & Tractor & & 0.617 & $\mathrm{~kg}$ \\
\hline & Agricultural machinery & & 3.29 & $\mathrm{~kg}$ \\
\hline & Shed & & 0.0053 & $\mathrm{~kg}$ \\
\hline & Diesel & & 43.79 & $\mathrm{~kg}$ \\
\hline Fertilizing & & & 1 & ha \\
\hline & Tractor & & 0.687 & $\mathrm{~kg}$ \\
\hline & Agricultural machinery & & 0.241 & $\mathrm{~kg}$ \\
\hline & Shed & & 0.00171 & $\mathrm{~kg}$ \\
\hline & Diesel & & 136.32 & $\mathrm{~kg}$ \\
\hline & Ammonium nitrate & & 1120 & $\mathrm{~kg}$ \\
\hline & Potassium chloride & & 560 & $\mathrm{~kg}$ \\
\hline & Phosphor & & 80 & $\mathrm{~kg}$ \\
\hline & Cow dung manure & & 1500 & $\mathrm{~kg}$ \\
\hline
\end{tabular}


Table A1. Cont.

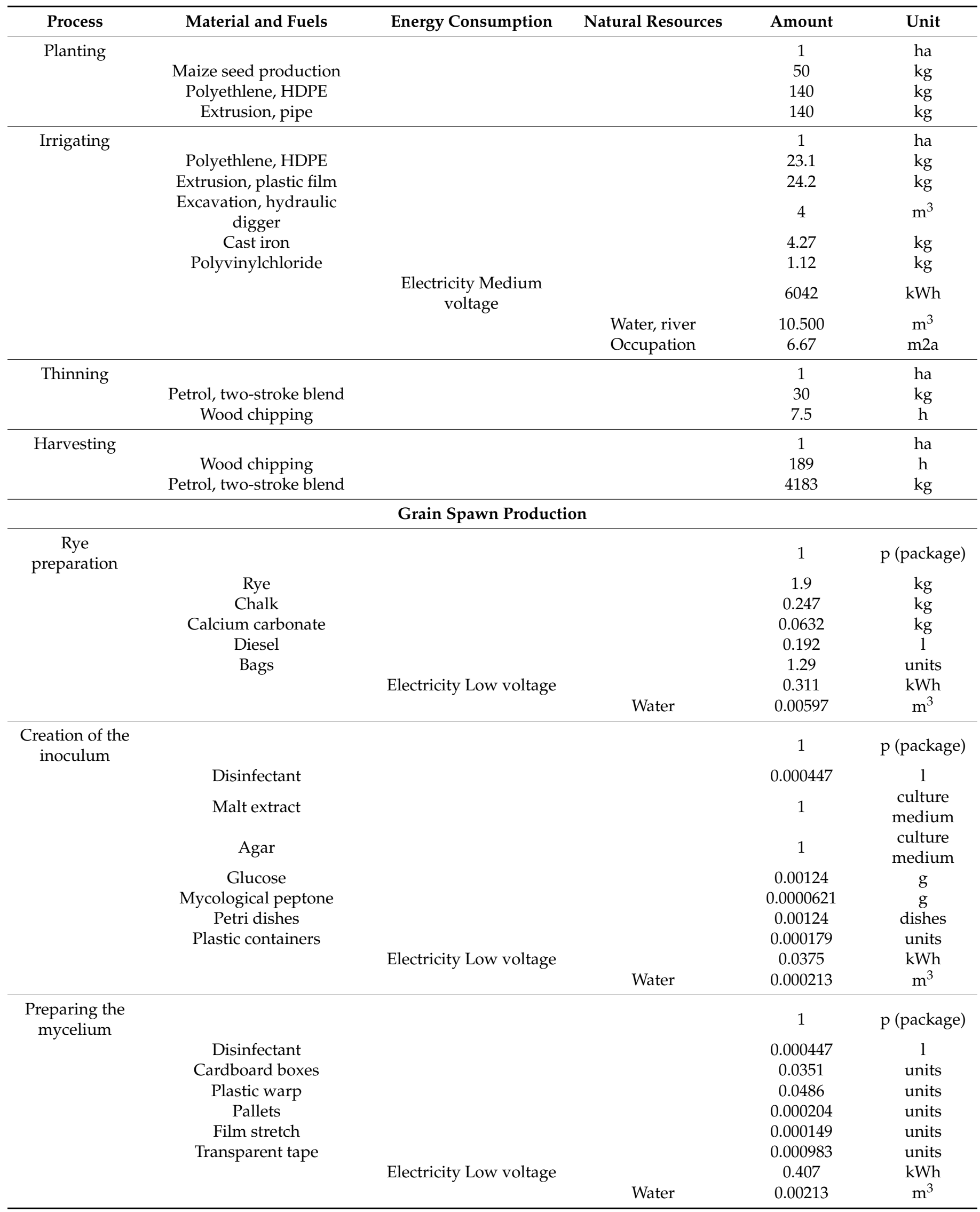


Table A1. Cont.

\begin{tabular}{|c|c|c|c|c|c|}
\hline Process & Material and Fuels & Energy Consumption & Natural Resources & Amount & Unit \\
\hline \multicolumn{6}{|c|}{ Bio-Composite } \\
\hline \multirow[t]{7}{*}{$\begin{array}{l}\text { Preparation of } \\
\text { the substrate }\end{array}$} & & & & 1 & $\mathrm{p}$ (sample) \\
\hline & Fiber of bamboo & & & 27.03 & $\mathrm{~g}$ \\
\hline & Water & & & 41.35 & g \\
\hline & Flour & & & 6.76 & $\mathrm{~g}$ \\
\hline & Hemp shives & & & 21.28 & $\mathrm{~g}$ \\
\hline & Water & & & 32.55 & $\mathrm{~g}$ \\
\hline & Flour & & & 5.32 & $\mathrm{~g}$ \\
\hline \multirow[t]{2}{*}{ Homogenization } & & & & 1 & $\mathrm{p}$ (sample) \\
\hline & & Electricity Low voltage & & 0.000756757 & $\mathrm{kWh}$ \\
\hline \multirow[t]{5}{*}{ Sterilization } & & & & 1 & p (sample) \\
\hline & Plastic bag & & & 2.16 & $\mathrm{~g}$ \\
\hline & & Electricity Low voltage & & 0.018 & kWh \\
\hline & Plastic bag & & & 1.70 & $\mathrm{~g}$ \\
\hline & & Electricity Low voltage & & 0.015 & kWh \\
\hline \multicolumn{2}{|c|}{ Inoculation/incubation } & & & 1 & p (sample) \\
\hline & Mycelium-bamboo & & & 11.35 & $\mathrm{~g}$ \\
\hline & Mycelium-hemp & & & 8.94 & $\begin{array}{l}8 \\
g\end{array}$ \\
\hline \multirow[t]{3}{*}{$\begin{array}{l}\text { Packing in the } \\
\text { mold }\end{array}$} & & & & 1 & p (sample) \\
\hline & PVC & & & 0.26 & $\mathrm{~g}$ \\
\hline & Extrusion plastic pipe & & & 0.26 & $\mathrm{~g}$ \\
\hline \multirow[t]{2}{*}{ Drying } & & & & 1 & $\mathrm{p}$ (sample) \\
\hline & & Electricity Low voltage & & 0.06913679 & $\mathrm{kWh}$ \\
\hline
\end{tabular}

Table A2. Transports included in the LCA.

\begin{tabular}{ccc}
\hline Material & Location & Distance \\
\hline Laboratory (arrival) & & $(\mathrm{km})$ \\
\hline Bamboo particles & Milan (IT) & $/$ \\
\hline Grain spawn & Tavullia (IT) & 350 \\
\hline
\end{tabular}

Table A3. Dynamic LCA inputs in the $\mathrm{DynCO}_{2}$ calculation tool.

\begin{tabular}{|c|c|c|}
\hline & $\mathrm{S}=60 ; \mathrm{CH}_{4}$ Captured & $\mathrm{S}=30 ; \mathrm{CH}_{4}$ Captured \\
\hline Year & $\begin{array}{l}\text { Relative } \\
\text { impact } \\
\mathrm{kg} \mathrm{CO}_{2-\text { eq }}\end{array}$ & $\begin{array}{l}\text { Relative } \\
\text { impact } \\
\mathrm{kg} \mathrm{CO}_{2-\mathrm{eq}}\end{array}$ \\
\hline 0 & 0 & 0 \\
\hline 1 & -1 & -1 \\
\hline 2 & -1 & -1 \\
\hline 3 & -1 & -1 \\
\hline 4 & -1 & -1 \\
\hline 5 & -1 & -1 \\
\hline 6 & -1 & -1 \\
\hline 7 & -1 & -1 \\
\hline 8 & -1 & -1 \\
\hline 9 & -1 & -1 \\
\hline 10 & -1 & -1 \\
\hline
\end{tabular}


Table A3. Cont.

\begin{tabular}{|c|c|c|}
\hline & $\mathrm{S}=60 ; \mathrm{CH}_{4}$ Captured & $\mathrm{S}=30 ; \mathrm{CH}_{4}$ Captured \\
\hline 11 & -1 & -1 \\
\hline 12 & -1 & -1 \\
\hline 13 & -1 & -1 \\
\hline 14 & -1 & -1 \\
\hline 15 & -1 & -1 \\
\hline 16 & -1 & -1 \\
\hline 17 & -1 & -1 \\
\hline 18 & -1 & -1 \\
\hline 19 & -1 & -1 \\
\hline 20 & -1 & -1 \\
\hline 21 & -1 & -1 \\
\hline 22 & -1 & -1 \\
\hline 23 & -1 & -1 \\
\hline 24 & -1 & -1 \\
\hline 25 & -1 & -1 \\
\hline 26 & -1 & -1 \\
\hline 27 & -1 & -1 \\
\hline 28 & -1 & -1 \\
\hline 29 & -1 & -1 \\
\hline 30 & -1 & -0.984135429 \\
\hline 31 & -1 & -0.970064173 \\
\hline 32 & -1 & -0.957470336 \\
\hline 33 & -1 & -0.946105234 \\
\hline 34 & -1 & -0.935771881 \\
\hline 35 & -1 & -0.926313222 \\
\hline 36 & -1 & -0.917603177 \\
\hline 37 & -1 & -0.909539802 \\
\hline 38 & -1 & -0.902040038 \\
\hline 39 & -1 & -0.89503569 \\
\hline 40 & -1 & -0.888470305 \\
\hline 41 & -1 & -0.882296767 \\
\hline 42 & -1 & -0.876475425 \\
\hline 43 & -1 & -0.870972627 \\
\hline 44 & -1 & -0.865759583 \\
\hline 45 & -1 & -0.860811455 \\
\hline 46 & -1 & -0.856106656 \\
\hline 47 & -1 & -0.851626277 \\
\hline 48 & -1 & -0.847353643 \\
\hline 49 & -1 & -0.84327395 \\
\hline 50 & -1 & -0.839373972 \\
\hline 51 & -1 & -0.83564183 \\
\hline 52 & -1 & -0.832066796 \\
\hline 53 & -1 & -0.828639137 \\
\hline 54 & -1 & -0.825349984 \\
\hline 55 & -1 & -0.822191223 \\
\hline 56 & -1 & -0.819155408 \\
\hline 57 & -1 & -0.816235679 \\
\hline 58 & -1 & -0.813425704 \\
\hline 59 & -1 & -0.810719616 \\
\hline 60 & -0.990958362 & -0.808111974 \\
\hline 61 & -0.982699712 & -0.805597713 \\
\hline 62 & -0.975093938 & -0.803172118 \\
\hline 63 & -0.968037611 & -0.800830783 \\
\hline 64 & -0.961448205 & -0.798569592 \\
\hline 65 & -0.955259588 & -0.796384689 \\
\hline 66 & -0.949418508 & -0.794272459 \\
\hline 67 & -0.943881847 & -0.792229507 \\
\hline 68 & -0.938614477 & -0.790252645 \\
\hline 69 & -0.933587589 & -0.788338869 \\
\hline
\end{tabular}


Table A3. Cont.

\begin{tabular}{|c|c|c|}
\hline & $\mathrm{S}=60 ; \mathrm{CH}_{4}$ Captured & $\mathrm{S}=30 ; \mathrm{CH}_{4}$ Captured \\
\hline 70 & -0.928777373 & -0.786485353 \\
\hline 71 & -0.924163996 & -0.784689431 \\
\hline 72 & -0.919730797 & -0.782948587 \\
\hline 73 & -0.91546365 & -0.781260445 \\
\hline 74 & -0.911350467 & -0.77962276 \\
\hline 75 & -0.907380808 & -0.778033407 \\
\hline 76 & -0.90354557 & -0.776490374 \\
\hline 77 & -0.899836742 & -0.774991756 \\
\hline 78 & -0.896247212 & -0.773535747 \\
\hline 79 & -0.892770612 & -0.772120632 \\
\hline 80 & -0.889401195 & -0.770744786 \\
\hline 81 & -0.886133735 & -0.769406662 \\
\hline 82 & -0.882963452 & -0.768104793 \\
\hline 83 & -0.879885944 & -0.766837781 \\
\hline 84 & -0.876897138 & -0.765604299 \\
\hline 85 & -0.873993246 & -0.76440308 \\
\hline 86 & -0.871170731 & -0.763232921 \\
\hline 87 & -0.86842628 & -0.762092672 \\
\hline 88 & -0.865756777 & -0.76098124 \\
\hline 89 & -0.863159285 & -0.75989758 \\
\hline 90 & -0.860631031 & -0.758840694 \\
\hline 91 & -0.858169388 & -0.757809633 \\
\hline 92 & -0.855771865 & -0.756803485 \\
\hline 93 & -0.853436094 & -0.755821384 \\
\hline 94 & -0.851159826 & -0.754862497 \\
\hline 95 & -0.848940916 & -0.753926031 \\
\hline 96 & -0.846777321 & -0.753011226 \\
\hline 97 & -0.844667091 & -0.752117353 \\
\hline 98 & -0.842608363 & -0.751243716 \\
\hline 99 & -0.840599357 & -0.750389648 \\
\hline 100 & -0.838638373 & -0.749554508 \\
\hline 101 & -0.83672378 & -0.748737684 \\
\hline 102 & -0.83485402 & -0.747938586 \\
\hline 103 & -0.833027598 & -0.747156651 \\
\hline 104 & -0.831243084 & -0.746391337 \\
\hline 105 & -0.829499105 & -0.745642124 \\
\hline 106 & -0.827794343 & -0.744908513 \\
\hline 107 & -0.826127535 & -0.744190023 \\
\hline 108 & -0.82449747 & -0.743486194 \\
\hline 109 & -0.822902981 & -0.742796582 \\
\hline 110 & -0.82134295 & -0.742120762 \\
\hline 111 & -0.819816303 & -0.741458322 \\
\hline 112 & -0.818322005 & -0.74080887 \\
\hline 113 & -0.816859063 & -0.740172024 \\
\hline 114 & -0.815426522 & -0.73954742 \\
\hline 115 & -0.814023462 & -0.738934705 \\
\hline 116 & -0.812648998 & -0.73833354 \\
\hline 117 & -0.811302278 & -0.737743599 \\
\hline 118 & -0.809982483 & -0.737164566 \\
\hline 119 & -0.808688821 & -0.736596138 \\
\hline 120 & -0.807420533 & -0.736038022 \\
\hline 121 & -0.806176884 & -0.735489935 \\
\hline 122 & -0.804957169 & -0.734951605 \\
\hline 123 & -0.803760705 & -0.734422769 \\
\hline 124 & -0.802586835 & -0.733903172 \\
\hline 125 & -0.801434925 & -0.73339257 \\
\hline 126 & -0.800304364 & -0.732890726 \\
\hline 127 & -0.799194561 & -0.732397411 \\
\hline 128 & -0.798104947 & -0.731912403 \\
\hline 129 & -0.797034972 & -0.73143549 \\
\hline
\end{tabular}


Table A3. Cont.

\begin{tabular}{|c|c|c|}
\hline & $\mathrm{S}=60 ; \mathrm{CH}_{4}$ Captured & $\mathrm{S}=30 ; \mathrm{CH}_{4}$ Captured \\
\hline 130 & -0.795984104 & -0.730966465 \\
\hline 131 & -0.794951831 & -0.730505127 \\
\hline 132 & -0.793937656 & -0.730051284 \\
\hline 133 & -0.792941101 & -0.729604749 \\
\hline 134 & -0.791961703 & -0.729165341 \\
\hline 135 & -0.790999015 & -0.728732884 \\
\hline 136 & -0.790052603 & -0.72830721 \\
\hline 137 & -0.78912205 & -0.727888154 \\
\hline 138 & -0.78820695 & -0.727475558 \\
\hline 139 & -0.787306912 & -0.727069268 \\
\hline 140 & -0.786421557 & -0.726669134 \\
\hline 141 & -0.785550518 & -0.726275012 \\
\hline 142 & -0.784693441 & -0.725886762 \\
\hline 143 & -0.78384998 & -0.725504249 \\
\hline 144 & -0.783019804 & -0.725127339 \\
\hline 145 & -0.78220259 & -0.724755907 \\
\hline 146 & -0.781398026 & -0.724389828 \\
\hline 147 & -0.780605808 & -0.724028982 \\
\hline 148 & -0.779825644 & -0.723673253 \\
\hline 149 & -0.779057249 & -0.723322526 \\
\hline 150 & -0.778300347 & -0.722976693 \\
\hline 151 & -0.777554671 & -0.722635647 \\
\hline 152 & -0.776819962 & -0.722299283 \\
\hline 153 & -0.776095968 & -0.721967503 \\
\hline 154 & -0.775382445 & -0.721640207 \\
\hline 155 & -0.774679157 & -0.721317301 \\
\hline 156 & -0.773985874 & -0.720998693 \\
\hline 157 & -0.773302372 & -0.720684293 \\
\hline 158 & -0.772628436 & -0.720374014 \\
\hline 159 & -0.771963854 & -0.72006777 \\
\hline 160 & -0.771308424 & -0.719765481 \\
\hline 161 & -0.770661945 & -0.719467064 \\
\hline 162 & -0.770024227 & -0.719172444 \\
\hline 163 & -0.769395081 & -0.718881542 \\
\hline 164 & -0.768774326 & -0.718594287 \\
\hline 165 & -0.768161785 & -0.718310605 \\
\hline 166 & -0.767557285 & -0.718030427 \\
\hline 167 & -0.766960661 & -0.717753685 \\
\hline 168 & -0.766371749 & -0.717480313 \\
\hline 169 & -0.765790391 & -0.717210245 \\
\hline 170 & -0.765216434 & -0.716943419 \\
\hline 171 & -0.764649728 & -0.716679774 \\
\hline 172 & -0.764090127 & -0.71641925 \\
\hline 173 & -0.763537491 & -0.716161789 \\
\hline 174 & -0.76299168 & -0.715907333 \\
\hline 175 & -0.762452562 & -0.715655829 \\
\hline 176 & -0.761920004 & -0.715407221 \\
\hline 177 & -0.761393881 & -0.715161457 \\
\hline 178 & -0.760874068 & -0.714918486 \\
\hline 179 & -0.760360444 & -0.714678259 \\
\hline 180 & -0.759852893 & -0.714440725 \\
\hline 181 & -0.759351299 & -0.714205838 \\
\hline 182 & -0.758855551 & -0.713973551 \\
\hline 183 & -0.75836554 & -0.713743819 \\
\hline 184 & -0.75788116 & -0.713516598 \\
\hline 185 & -0.757402308 & -0.713291844 \\
\hline 186 & -0.756928883 & -0.713069515 \\
\hline 187 & -0.756460787 & -0.71284957 \\
\hline 188 & -0.755997923 & -0.712631969 \\
\hline 189 & -0.755540199 & -0.712416673 \\
\hline
\end{tabular}


Table A3. Cont.

\begin{tabular}{ccc}
\hline & $\mathbf{S}=\mathbf{6 0} ; \mathbf{C H}_{\mathbf{4}}$ Captured & $\mathbf{S}=\mathbf{3 0} ; \mathbf{C H}_{\mathbf{4}}$ Captured \\
\hline 190 & -0.755087524 & -0.712203643 \\
191 & -0.754639807 & -0.711992841 \\
192 & -0.754196963 & -0.711784231 \\
193 & -0.753758907 & -0.711577778 \\
194 & -0.753325555 & -0.711373446 \\
195 & -0.752896828 & -0.711171201 \\
196 & -0.752472647 & -0.710971009 \\
198 & -0.752052934 & -0.710772839 \\
199 & -0.751637614 & -0.710576657 \\
200 & -0.751226613 & -0.710382433 \\
\hline
\end{tabular}

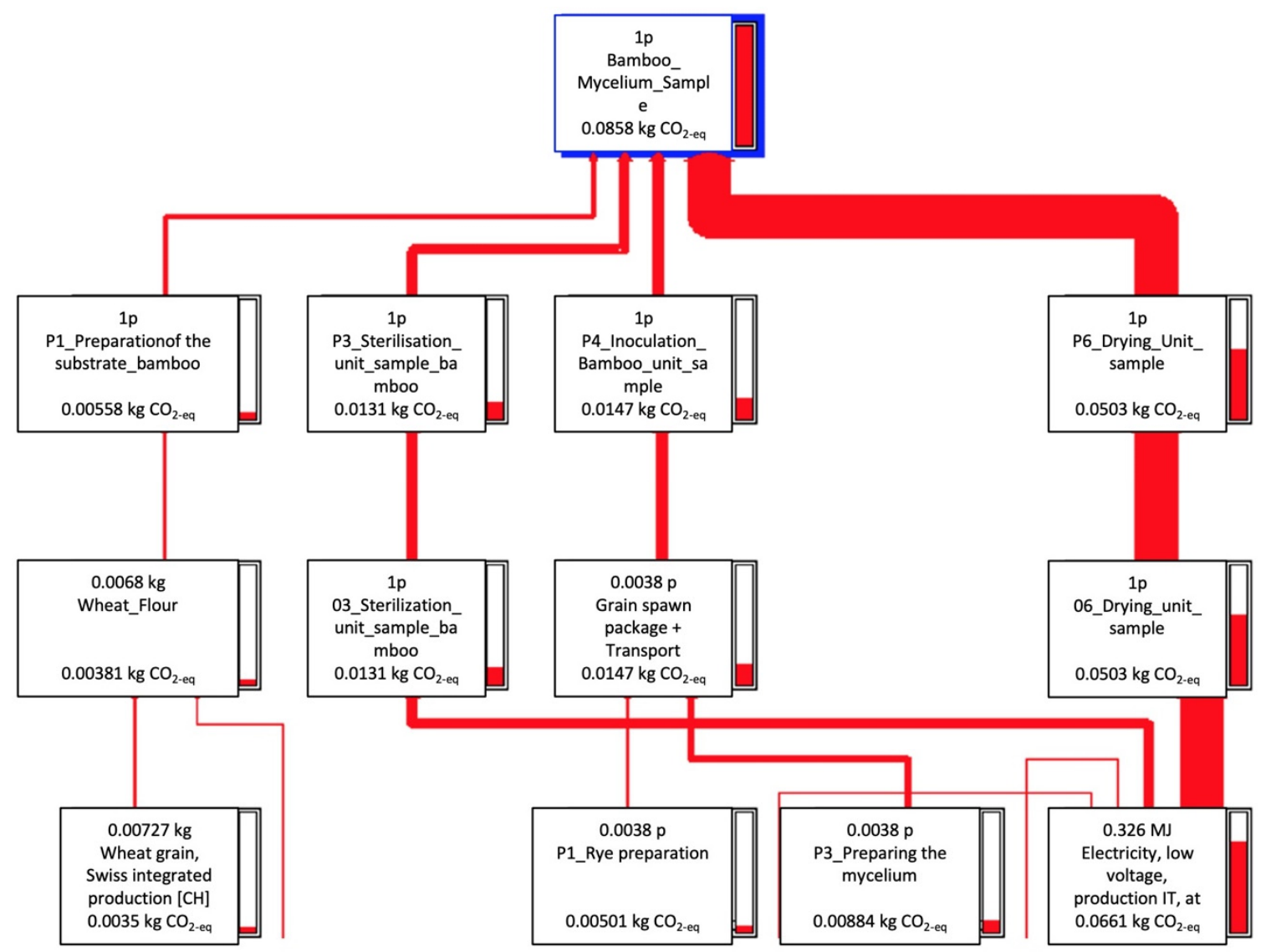

Figure A1. Network flow representation of process contribution to GWP.

\section{References}

1. Anderson, J.E.; Wulfhorst, G.; Lang, W. Energy analysis of the built environment-A review and outlook. Renew. Sustain. Energy Rev. 2015, 44, 149-158. [CrossRef]

2. Junnila, S.I. Empirical comparison of process and economic input-output life cycle assessment in service industries. Environ. Sci. Technol. 2006, 40, 7070-7076. [CrossRef] [PubMed]

3. Schandl, H.; Fischer-Kowalski, M.; West, J.; Giljum, S.; Dittrich, M.; Eisenmenger, N.; Geschke, A.; Lieber, M.; Wieland, H.; Schaffartzik, A.; et al. Global material flows and resource productivity forty years of evidence. J. Ind. Ecol. 2018, 22, 827-838. [CrossRef]

4. $\quad$ Röck, M.; Saade, M.R.M.; Balouktsi, M.; Rasmussen, F.N.; Birgisdottir, H.; Frischknecht, R.; Habert, G.; Lützkendorf, T.; Passer, A. Embodied GHG emissions of buildings-The hidden challenge for effective climate change mitigation. Appl. Energy 2020, 258, 114107. [CrossRef]

5. Amiri, A.; Emami, N.; Ottelin, J.; Sorvari, J.; Marteinsson, B.; Heinonen, J.; Junnila, S. Embodied emissions of buildingsA forgotten factor in green building certificates. Energy Build. 2021, 241, 110962. [CrossRef] 
6. Churkina, G.; Organschi, A.; Reyer, C.P.O.; Ruff, A.; Vinke, K.; Liu, Z.; Reck, B.K.; Graedel, T.E.; Schellnhuber, H.J. Buildings as a global carbon sink. Nat. Sustain. 2020, 3, 269-276. [CrossRef]

7. Pittau, F.; Krause, F.; Lumia, G.; Habert, G. Fast-growing bio-based materials as an opportunity for storing carbon in exterior walls. Build. Environ. 2018, 129, 117-129. [CrossRef]

8. Göswein, V.; Reichmann, J.; Habert, G.; Pittau, F. Land availability in Europe for a radical shift toward bio-based construction. Sustain. Cities Soc. 2021, 70, 102929. [CrossRef]

9. Pongon, R.S.; Aranico, E.C.; Dagoc, F.L.S.; Amparado, R.F., Jr. Carbon Stock Assessment of Bamboo Plantations in Northern Mindanao, Philippines. J. Biodivers. Environ. Sci. 2016, 9, 97-112.

10. Liese, W. Bamboo as carbon sink-fact or fiction? J. Bamboo Ratt. 2009, 8, 103-114.

11. Vogtländer, J.G.; van der Lugt, P. The Environmental Impact of Industrial Bamboo Products: Life Cycle Assessment and Carbon Sequestration. 2015. Available online: https://www.inbar.int/resources/inbar_publications/the-environmental-impact-ofindustrial-bamboo-products-life-cycle-assessment-and-carbon-sequestration/ (accessed on 10 March 2021).

12. Scurlock, J.M.O.; Dayton, D.C.; Hames, B. Bamboo: An overlooked biomass resource? Biomass Bioenergy 2000, 19, $229-244$. [CrossRef]

13. Depuydt, D.E.C.; Billington, L.; Fuentes, C.; Sweygers, N.; Dupont, C.; Appels, L.; Ivens, J.; van Vuure, A.W. European bamboo fibres for composites applications, study on the seasonal influence. Ind. Crops Prod. 2019, 133, 304-316. [CrossRef]

14. Van Wassenhove, R.; De Laet, L.; Vassilopoulos, A.P. A 3D printed bio-composite removable connection system for bamboo spatial structures. Compos. Struct. 2021, 269, 114047. [CrossRef]

15. Caldas, L.; Pittau, F.; Andreola, V.; Habert, G.; Saraiva, A.; Filho, R.T. Dynamic life cyle carbon assessment of three bamboo bio-concretes in Brazil. Acad. J. Civ. Eng. 2019, 37, 593-599.

16. Liu, L.; Li, H.; Lazzaretto, A.; Manente, G.; Tong, C.; Liu, Q.; Li, N. The development history and prospects of biomass-based insulation materials for buildings. Renew. Sustain. Energy Rev. 2017, 69, 912-932. [CrossRef]

17. Sandak, A.; Sandak, J.; Brzezicki, M.; Kutnar, A. Bio-Based Building Skin; Environmental Footprints and Eco-Design of Products and Processes; Springer: Singapore, 2019.

18. Haneef, M.; Ceseracciu, L.; Canale, C.; Bayer, I.S.; Heredia-Guerrero, J.A.; Athanassiou, A. Advanced Materials from Fungal Mycelium: Fabrication and Tuning of Physical Properties. Sci. Rep. 2017, 7, 41292. [CrossRef]

19. Attias, N.; Danai, O.; Abitbol, T.; Tarazi, E.; Ezov, N.; Pereman, I.; Grobman, Y.J. Mycelium bio-composites in industrial design and architecture: Comparative review and experimental analysis. J. Clean. Prod. 2020, 246, 119037. [CrossRef]

20. Lelivelt, R. The Mechanical Possibilities of Mycelium Materials-Eindhoven University of Technology Research Portal. 2015. Available online: https:/ / pure.tue.nl/ws/portalfiles/portal/47018924/793800-1.pdf (accessed on 24 August 2021).

21. Jones, M.; Bhat, T.; Kandare, E.; Thomas, A.; Joseph, P.; Dekiwadia, C.; Yuen, R.; John, S.; Ma, J.; Wang, C.H. Thermal Degradation and Fire Properties of Fungal Mycelium and Mycelium-Biomass Composite Materials. Sci. Rep. 2018, 8, 17583. [CrossRef]

22. Breton, C.; Blanchet, P.; Amor, B.; Beauregard, R.; Chang, W.S. Assessing the climate change impacts of biogenic carbon in buildings: A critical review of two main dynamic approaches. Sustainability 2018, 10, 20. [CrossRef]

23. Hoxha, E.; Passer, A.; Saade, M.R.M.; Trigaux, D.; Shuttleworth, A.; Pittau, F.; Allacker, K.; Habert, G. Biogenic carbon in buildings: A critical overview of LCA methods. Build. Cities 2020, 1, 504-524. [CrossRef]

24. Levasseur, A.; Lesage, P.; Margni, M.; Samson, R. Biogenic Carbon and Temporary Storage Addressed with Dynamic Life Cycle Assessment. J. Ind. Ecol. 2013, 17, 117-128. [CrossRef]

25. Brandão, M.; Levasseur, A.; Kirschbaum, M.U.F.; Weidema, B.P.; Cowie, A.L.; Jørgensen, S.V.; Hauschild, M.Z.; Pennington, D.W.; Chomkhamsri, K. Key issues and options in accounting for carbon sequestration and temporary storage in life cycle assessment and carbon footprinting. Int. J. Life Cycle Assess. 2013, 18, 230-240. [CrossRef]

26. Correia, M.; Dipasquale, L.; Mecca, S. Heritage for Tomorrow; Firenze University Press: Firenze, Italy, 2014.

27. Camere, S.; Karana, E. Fabricating materials from living organisms: An emerging design practice. J. Clean. Prod. 2018, 186, 570-584. [CrossRef]

28. Çimen, Ö. Construction and built environment in circular economy: A comprehensive literature review. J. Clean. Prod. 2021, 305, 127180. [CrossRef]

29. Elsacker, E.; Vandelook, S.; Brancart, J.; Peeters, E.; De Laet, L. Mechanical, physical and chemical characterisation of myceliumbased composites with different types of lignocellulosic substrates. PLoS ONE 2019, 14, e0213954. [CrossRef]

30. Jones, M.; Mautner, A.; Luenco, S.; Bismarck, A.; John, S. Engineered mycelium composite construction materials from fungal biorefineries: A critical review. Mater. Des. 2020, 187, 108397. [CrossRef]

31. Design Ecovative. Ecovative Design Mushroom Packaging Life Cycle Assessment. 2016. Available online: https://www.rit.edu/ affiliate/nysp2i/sites/rit.edu.affiliate.nysp2i/files/docs/resources/Ecovative_Design_Compares_Environmental_Impact_of_ Packaging_Materials.pdf (accessed on 11 September 2021).

32. Girometta, C.; Picco, A.M.; Baiguera, R.M.; Dondi, D.; Babbini, S.; Cartabia, M.; Pellegrini, M.; Savino, E. Physico-mechanical and thermodynamic properties of mycelium-based biocomposites: A review. Sustainability 2019, 11, 281. [CrossRef]

33. Hilton, B. Using LCA to Prioritize Process Changes: A Mushroom Packaging LCA Case Study. Available online: https: / / studylib.net/doc/18078297/remanufacturing-lca (accessed on 1 September 2021).

34. Jones, M.; Gandia, A.; John, S.; Bismarck, A. Leather-like material biofabrication using fungi. Nat. Sustain. 2021, 4, 9-16. [CrossRef] 
35. Vivai OnlyMoso di Fabrizio Pecci, 2021. Onlymoso [WWW Document]. Available online: https://onlymoso.it/ (accessed on 26 November 2021).

36. PRé, 2021. SimaPro 9.2. Available online: https://simapro.com/wp-content/uploads/2021/07/SimaPro920WhatIsNew.pdf (accessed on 1 July 2021).

37. Moreno Ruiz, E.; Valsasina, L.; Fitzgerald, D.; Brunner, F.; Vadenbo, C.; Bauer, C.; Bourgault, G.; Symeonidis, A.; Wernet, G. Documentation of Changes Implemented in the Ecoinvent Database v3. 4. Ecoinvent. Zürich 2017, Switzerland 8. Available online: https: / / ecoinvent.org/wp-content/uploads/2021/09/Change-Report-v3.8.pdf (accessed on 27 July 2021).

38. Lin, X.C.; Chow, T.Y.; Chen, H.H.; Liu, C.C.; Chou, S.J.; Huang, B.L.; Kuo, C.I.; Wen, C.K.; Huang, L.C.; Fang, W. Understanding bamboo flowering based on large-scale analysis of expressed sequence tags. Genet. Mol. Res. 2010, 9, 1085-1093. [CrossRef]

39. Appels, F.V.W.; Camere, S.; Montalti, M.; Karana, E.; Jansen, K.M.B.; Dijksterhuis, J.; Krijgsheld, P.; Wösten, H.A.B. Fabrication factors influencing mechanical, moisture- and water-related properties of mycelium-based composites. Mater. Des. 2019, 161, 64-71. [CrossRef]

40. Elsacker, E.; Vandelook, S.; Van Wylick, A.; Ruytinx, J.; De Laet, L.; Peeters, E. A comprehensive framework for the production of mycelium-based lignocellulosic composites. Sci. Total Environ. 2020, 725, 138431. [CrossRef] [PubMed]

41. ISO 22007-2; Plastics-Determination of Thermal Conductivity and Thermal Diffusivity_Part 2: Transient Plane Heat Source (Hot Disc) Method. ISO: Genève, Switzerland, 2015.

42. Atanasiu, B.; Maio, J.; Staniaszek, D.; Kouloumpi, I.; Kenkmann, T. Overview of the EU-27 Building Policies and Programs. Factsheets on the Nine Entranze Target Countries. 2014. Available online: https://www.entranze.eu/files/downloads/D5_1_3 /ENTRANZE_Integration_of_report_D5.1_D5.2_D5.3_final.pdf (accessed on 10 October 2021).

43. Di Milano, P. MaBa.SAPERlab [WWW Document]. 2020. Available online: https://www.dabc.polimi.it/en/abclab/le-unita/ mabasaperlab / (accessed on 26 November 2021).

44. ISO 14040; Environmental Management-Life Cycle Assessment-Principles and Framework. ISO: Genève, Switzerland, 2006.

45. Guest, G.; Cherubini, F.; Strømman, A.H. Global Warming Potential of Carbon Dioxide Emissions from Biomass Stored in the Anthroposphere and Used for Bioenergy at End of Life. J. Ind. Ecol. 2013, 17, 20-30. [CrossRef]

46. European Commission, Official Journal of EU, L 312, 19.11.2008. Directive 2008/98/EC of the European Parliament and of the Council of 19 November 2008 on Waste and Repealing Certain Directives. Available online: http: / / eur-lex.europa.eu/LexUriServ/ LexUriServ.do?uri \protect\$relax \protect\{begingroup1 \endgroup \@@over4\}\$OJ:L:2008:312:0003:0030:en:PDF (accessed on 5 August 2021).

47. Stoeva, K.; Alriksson, S. Influence of recycling programmes on waste separation behaviour. Waste Manag. 2017, 68, 732-741. [CrossRef] [PubMed]

48. Vaverková, M.D. Landfill impacts on the environment-Review. Geosciences 2019, 9, 431. [CrossRef]

49. Dai, X.; Hua, Y.; Liu, R.; Chen, S.; Li, H.; Dai, L.; Cai, C. Biomethane production by typical straw anaerobic digestion: Deep insights of material compositions and surface properties. Bioresour. Technol. 2020, 313, 123643. [CrossRef]

50. Levasseur, A. 2010. New Generation Carbon Footprinting, CIRAIG [WWW Document]. Available online: https://ciraig.org/pdf/ DYNCO2_InstructionManual.pdf (accessed on 4 July 2021).

51. Sébastien, L.; Goulouti, K.; Favre, D.; Giorgi, M.; Padey, P.; Volland, B.; Farsi, M.; Habert, G.; Galimshina, A. Analysis of Lifetimes of Building Elements in the Literature and in Renovation Practices and Sensitivity Analyses on Building LCA \& LCC. Erneuern! Sanierungsstrategien Für den Gebäudepark. 2020. Available online: https://www.researchgate.net/publication/349139276_ Analysis_of_lifetimes_of_building_elements_in_the_literature_and_in_renovation_practices_and_sensitivity_analyses_on_ building_LCA_LCC\#fullTextFileContent (accessed on 2 November 2021).

52. Göswein, V.; Silvestre, J.D.; Sousa Monteiro, C.; Habert, G.; Freire, F.; Pittau, F. Influence of material choice, renovation rate, and electricity grid to achieve a Paris Agreement-compatible building stock: A Portuguese case study. Build. Environ. 2021, 195, 107773. [CrossRef]

53. Yadav, M.; Agarwal, M. Bio-based building materials for sustainable future: An overview. Mater. Today Proc. 2021, 43, $2895-2902$. [CrossRef] 